\title{
Environmental factors associated with autism spectrum disorder: a scoping review for the years 2003-2013
}

Michelle Ng, MPH (1,2); Joanne G. de Montigny, MHA (3); Marianna Ofner, PhD (1,2); Minh T. Do, PhD (1,2)

This article has been peer reviewed.

\begin{abstract}
Introduction: The number of children diagnosed with autism spectrum disorder (ASD) has been rapidly rising in the past decade. The etiology of this disorder, however, is largely unknown, although the environmental relative to the genetic contribution is substantial. We conducted a scoping review to comprehensively assess the current state of knowledge of the environmental factors present from preconception to early life associated with ASD, and to identify research gaps.
\end{abstract}

Methods: We searched electronic databases MEDLINE, PsycINFO and ERIC for articles on potential risk factors or protective factors from the physical and social environments associated with ASD and its subclassifications published between 1 January, 2003, and 12 July, 2013. We categorized articles into broad themes: chemical, physiological, nutritional and social factors, based on environmental exposure.

Results: We identified over 50000 publications, but after ineligible studies were screened out, 315 articles remained. Most of these studies examined physiological factors, followed closely by chemical factors, and to a much lesser extent, nutritional and social factors, associated with ASD. Despite a vast literature and many heterogeneous studies, several risk factors emerged consistently: chemical factors such as traffic-related air pollutants; physiological factors including advanced parental age, preterm birth, low birth weight, hyperbilirubinemia and clustering of pregnancy complications; and maternal immigrant status. Despite extensive research on vaccines, findings overwhelmingly demonstrate no support for an association with ASD.

Conclusion: The lack of consistency, temporality and specificity of associations between environmental factors and ASD remains the largest barrier to establishing causal relationships. More robust research is required to resolve inconsistencies in the literature. Future research should explore underlying mechanisms of associations between the risk factors that we identified and ASD.

Keywords: ASD, autism spectrum disorder, autism, environmental exposure, etiology

\section{Introduction}

Autism spectrum disorder (ASD) is a group of neurodevelopmental disorders with varying levels of severity in impairment in social communication and interaction, and restricted repetitive behaviours, interests and activities. ${ }^{1}$ The number of children with ASD has been rapidly rising in the past decade. ${ }^{2}$ In the US, the number of cases increased by $123 \%$ from 2002 to
2010, with an estimated prevalence of 1 in 68 children aged 8 years. ${ }^{3}$ In Canada, from 2003 to 2010, increases of $70 \%$ and $95 \%$ were reported in Prince Edward Island and Southeastern Ontario, respectively, with corresponding prevalence of 1 in 106 and 1 in 63 children aged 6 to 9 years in 2010. ${ }^{4}$ Greater ASD awareness and changes in diagnostic criteria may be contributing factors, ${ }^{5}$ but explain only a portion of the increased prevalence. ${ }^{6,7}$ Although the

\section{Highlights}

- The environmental factors most commonly studied in association with ASD were physiological and chemical factors. Research on nutritional and social factors is limited.

- Older parental age, low birth weight, premature birth, neonatal jaundice and clustering of pregnancy complications were consistently reported to be associated with ASD.

- Evidence for the association between traffic-related air pollutants and ASD has been emerging.

- Maternal immigrant status was consistently associated with ASD.

- The lack of consistency, temporality and specificity of associations between environmental factors and ASD remains the largest barrier to establishing causal relationships.

genetic contribution to the etiology of ASD is known, ${ }^{8}$ the rapid increase in ASD prevalence cannot be fully attributed to genetics alone.

A twin concordance study has shown that shared environmental factors account for $58 \%$ of the variance in liability for ASD. ${ }^{8}$ Furthermore, prenatal and early infancy periods are known to be critical periods of growth during which children are particularly vulnerable to harmful effects of environmental hazards that can result in childhood diseases. ${ }^{9}$ However, the role of environmental factors in the onset of ASD is still largely unknown. Of the reviews that have explored possible risk factors of ASD to date, ${ }^{10-16}$ none have comprehensively examined the entire scope of the environmental contribution to ASD. 
The purpose of this scoping review is to comprehensively assess the current state of knowledge of environmental factors associated with ASD incidence and to identify research gaps. Specifically, we aim to identify any environmental exposures, including chemical, physiological, nutritional and social factors, from preconception to early-life periods associated with ASD.

\section{Methods}

This review followed Arksey and O'Malley's scoping framework. ${ }^{17}$ We searched the electronic databases MEDLINE, PsycINFO and ERIC for primary studies or reviews on potential modifiable risk factors or protective factors from the physical or social environment associated with ASD. We developed a comprehensive list of medical subject headings and keywords with the help of a librarian at the University of Ottawa. Search terms were centred on two main concepts: (1) ASD and its subclassifications, including pervasive development disorder not otherwise specified (PDDNOS), autism and Asperger syndrome; and (2) environmental exposures or risk factors, maternal condition before or during pregnancy, and paternal preconception condition. The search strategy was adapted appropriately to the other databases, PsycINFO and ERIC, using their corresponding subject heading terms. Searches were limited to articles with an abstract published in the English language with a publication date between 1 January, 2003, and 12 July, 2013, to focus on current literature. We excluded articles if the epidemiological associations they described included comorbidities, the result of living with ASD or biochemical pathways not directly related to etiology; we also excluded studies that used animal models, cell studies and strictly genetic studies. Commentaries, editorials, letters, news articles and articles that did not primarily focus on ASD etiology were also filtered out.

We categorized journal articles into broad themes: chemical, physiological, nutritional, social and other, based on the nature of the environmental exposure examined. Within each broad theme, we identified recurring subthemes. We abstracted publication year, study design, study population, exposure, confounders, case definition and main findings from each full-text article. The review process resulted in 315 articles for final analysis (Figure 1). Our review focussed mainly on primary studies and systematic reviews.

\section{Results}

The literature encompassed a wide scope of research investigating potential environmental risk factors associated with ASD. Research has been conducted worldwide; many studies were concentrated in the Nordic countries, the United States, the United Kingdom, Australia and Japan. Most studies examined physiological factors, followed closely by chemical factors, and then nutritional and social factors associated with ASD (Table 1; Figure 2). There was some overlap between these areas as several studies examined a combination of factors; about $14 \%$ of the articles (44/315) explored more than one theme. The largest proportion of these examined chemical and nutritional factors (heavy metal exposures and mineral deficiencies). Figure 3 shows the frequency of articles published, by research area and publication period. Most articles were published between 2009 and 2013, with the exception of articles on vaccines, most of which were published between 2003 and 2008 .

\section{Chemical dimension}

The chemical factors we investigated in association with ASD included environmental chemicals, vaccines, medication and substance abuse. Articles on exposure to environmental chemicals and vaccines (both primarily concerning postnatal exposure) each accounted for approximately $40 \%$ of the chemical dimension (Figure 2).

\section{Environmental chemicals}

The environmental chemicals we examined in association with ASD were predominantly heavy metals, found in biological samples from children, followed by air pollutants; both mainly investigated in case-control studies (Table 2). A small number of the studies and/or reviews explored associations with prenatal or perinatal exposure to occupational chemicals $^{18,19}$ and pesticides..$^{20,21}$

\section{Heavy metals}

Many studies examined biomarkers of postnatal exposure to heavy metals, particularly mercury, in children with ASD or autism compared to children without ASD. Assessing baby teeth, particularly tooth enamel, which begins to form in utero and continues up to one year after birth, ${ }^{22}$ can also help determine prenatal exposure. The five most commonly studied heavy metals were mercury, lead, cadmium, aluminum and arsenic.

\section{Mercury: biomarkers and sources of exposure}

Mercury has received considerable attention because of the similarities in the symptoms of mercury poisoning and autism. ${ }^{23}$ Biomarkers of mercury exposure in children with autism were primarily examined by measuring levels in hair (14 studies), blood (4), urine (4), teeth (2) and nails (1). However, findings were largely inconsistent (Table 3 ). Urinary porphyrins, intermediates in heme biosynthesis, have also been studied as potential biomarkers for mercury exposure in people with autism, as increased porphyrins have been associated with prolonged mercury exposure. ${ }^{24}$ Elevated porphyrins have been found in children with autism compared to children without autism, ${ }^{25-29}$ and may increase with severity of autistic symptoms. ${ }^{30,31}$ Although nearly all studies attributed these findings to mercury exposure, none actually measured mercury exposure except for one study, which found no association with ASD despite finding a correlation between elevated porphyrins and ASD. ${ }^{27}$

Few of the studies in this review investigated mercury exposure from sources other than thimerosal in vaccines and $\mathrm{Rh}$ immune globulins. Ecological studies have demonstrated an association between environmentally released mercury emissions and significant increases in autism rates, ${ }^{32}$ which may be related to residential distance from mercury pollution sources such as industrial or power plant facilities. ${ }^{33}$ Other studies have examined other prenatal and postnatal mercury exposure sources in relation to ASD, such as maternal dental amalgam fillings ${ }^{27,34,35}$ and maternal or child consumption of seafood, ${ }^{27,36,37}$ with inconsistent findings.

A 2012 systematic review concluded that, due to methodological issues such as small sample size and inconsistent case ascertainment, the relationship between mercury exposure and ASD remains unclear. ${ }^{38}$ Furthermore, according to a meta-analysis, hair mercury analysis may not be reliable. ${ }^{39}$ The use of blood or hair mercury levels as accurate measures of 
FIGURE 1

Process for searching and screening research on autism spectrum disorders

found in three electronic databases, published between 2003 and 2013

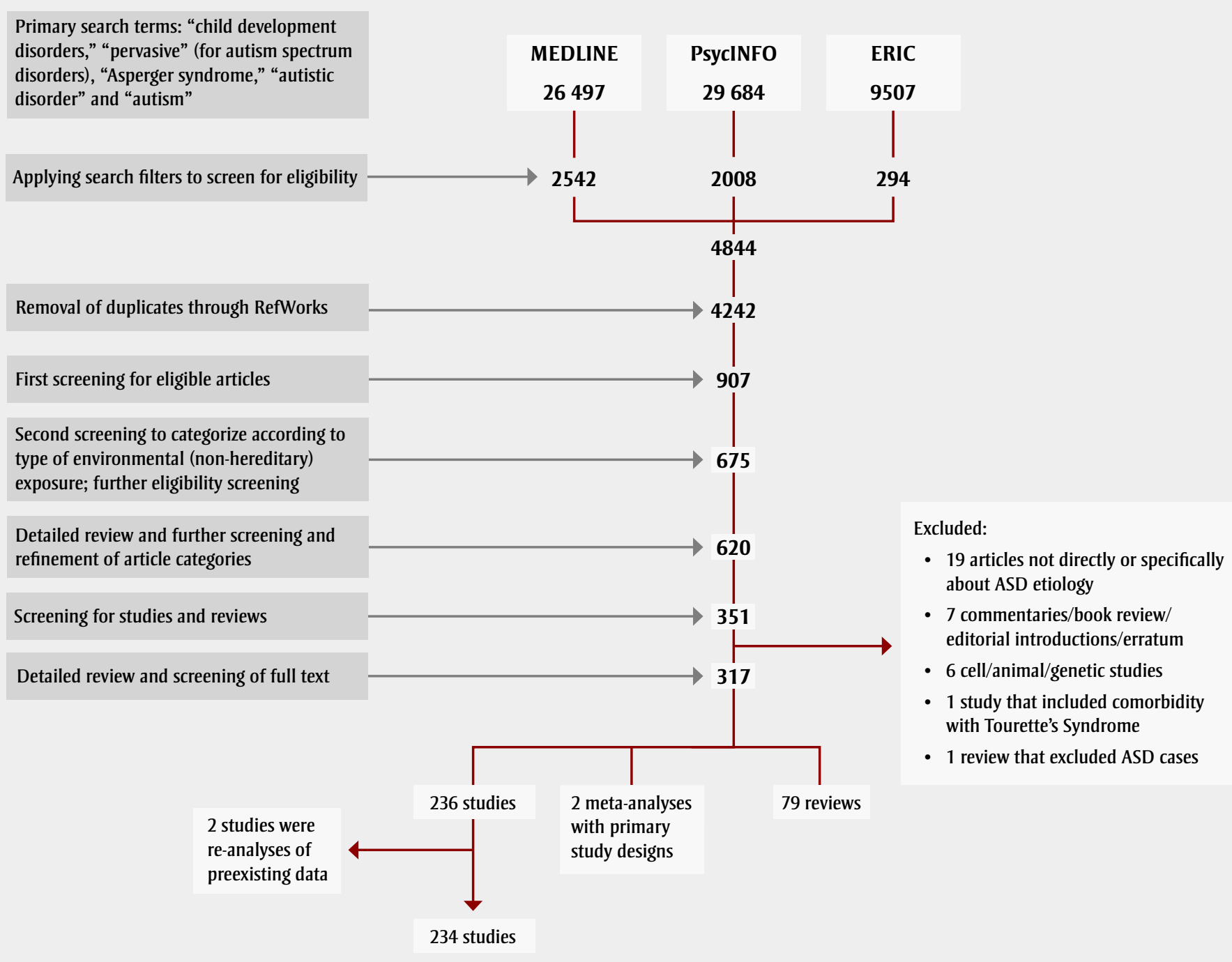

TABLE 1

Final selection of 315 research articles on associations between environmental factors and autism spectrum disorder, by dimension and article type

\begin{tabular}{lrc}
\hline Dimension & \# of studies & \# of reviews \\
\hline Chemical & 94 & 44 \\
\hline Physiological & $125^{\mathrm{a}}$ & 36 \\
\hline Nutritional & 23 & 10 \\
\hline Social & 25 & 7 \\
\hline Other & 4 & 2 \\
\hline
\end{tabular}

Note: Some studies/reviews explored more than one theme, and some studies also had a meta-analysis component- totals do not add up to 315 .

a 124 unique studies. Two studies used the same data. prenatal and early-life exposure is questionable ${ }^{38}$ considering mercury's relatively short half-life. ${ }^{40,41}$

\section{Other heavy metals}

Sixteen studies examined the association between exposure to other heavy metals and ASD or autism by measuring levels mainly in hair samples. Lead, cadmium, aluminum and arsenic were the moststudied heavy metals in children with ASD or autism, but there were conflicting findings (Table 3 ). Most studies found no significant association between aluminum and ASD. None of these studies investigated possible exposure sources.

\section{Pollutants}

Only a few studies investigated the relationship between drinking water content and autism. ${ }^{42,43}$ However, five populationbased case-control studies, mostly in California, investigated air pollutant exposure while controlling for sociodemographic factors. Relatively consistent evidence for an association between prenatal, perinatal and/or early-life trafficrelated air pollutant exposures and ASD or autism was found ${ }^{44-48}$ (Table 4). Exposure to traffic-related air pollution can result in respiratory and cardiovascular disease and certain neurological outcomes by triggering inflammation and oxidative stress, ${ }^{49-51}$ which are common physiological abnormalities observed in children with ASD. Maternal residence in areas with higher levels of exposure to nitrogen dioxide, ${ }^{44,47}$ exposure to particulate matter less than $2.5 \mu^{44,47}$ and exposure to nitric oxide ${ }^{44}$ 
FIGURE 2

Final selection of articles ${ }^{\mathrm{a}}$ on associations between environmental factors and autism spectrum disorder, by subject and article type

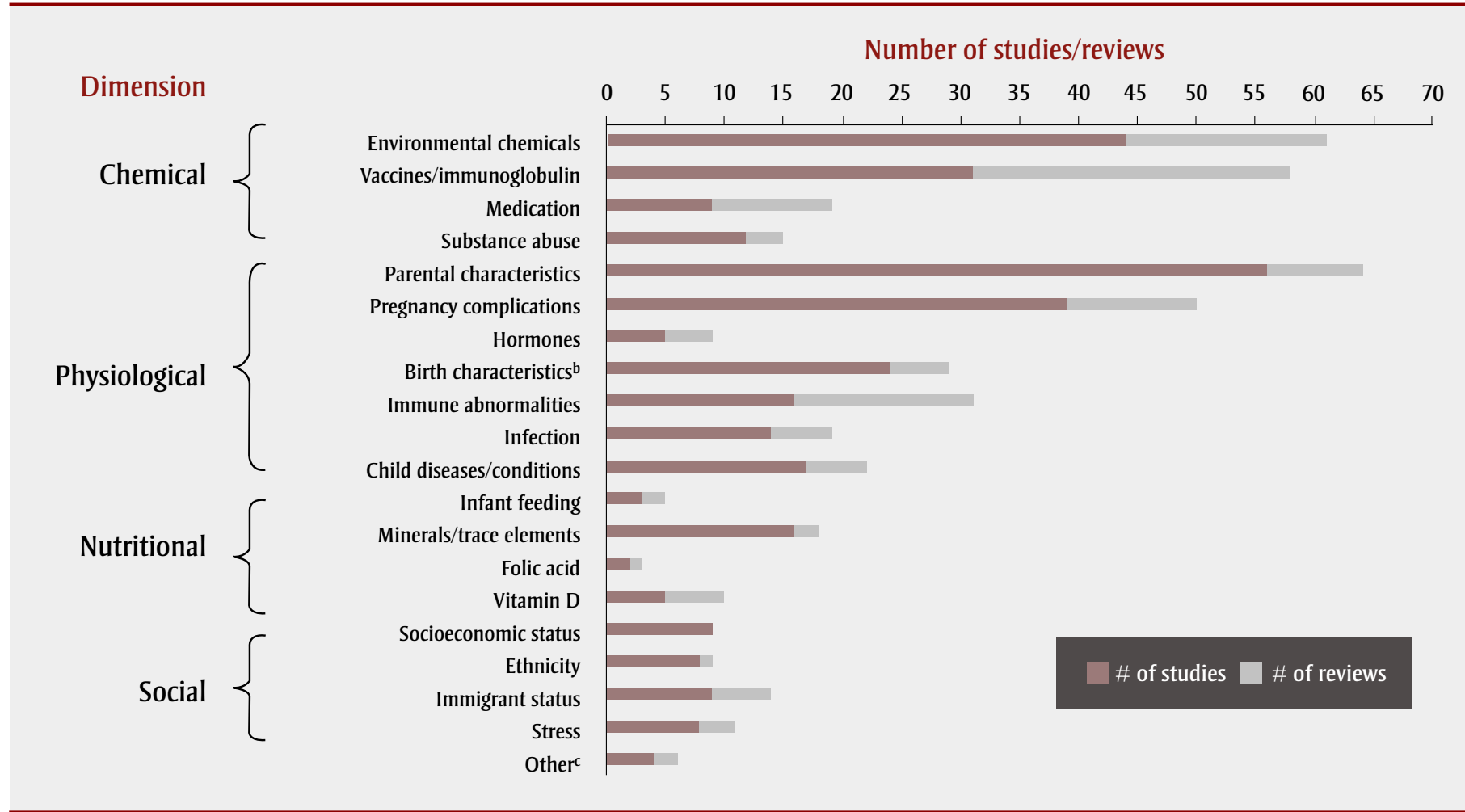

${ }^{a}$ Includes an article that was a primary research study and a meta-analysis.

${ }^{\mathrm{b}}$ Includes birth order/parity, spacing, seasonality and multiple births.

${ }^{\mathrm{c}}$ Includes prenatal ultrasound, electromagnetic radiation and geographical clustering.

during gestation and/or the early life of the child were associated with having a child with autism. Also, residing near a freeway during pregnancy, especially during the third trimester, was associated with having children with autism. ${ }^{46}$ Findings for prenatal exposure to other pollutants including ozone and particulate matter less than $10 \mu \mathrm{m}^{44,47}$ or prenatal and/or perinatal exposure to specific chlorinated solvents and metals ${ }^{45,48}$ in relation to autism or ASD have been inconsistent so far.

\section{Vaccines and medication}

\section{Vaccines}

Measles Mumps Rubella (MMR) vaccination Since the publication of the Wakefield case series study, ${ }^{52}$ which found an increased prevalence of a new variant of autism characterized by gastrointestinal disorders and developmental regression, the safety of MMR vaccine has been questioned, although this paper was later retracted due to false data. Nine case-control and two time-series studies ${ }^{53-63}$ and two systematic reviews ${ }^{64,65}$ found no significant association between MMR vaccine and
ASD or autism, although another timeseries study did. ${ }^{66}$ A systematic review found that studies with the lowest bias based on study quality criteria did not support a causal association. ${ }^{64}$ Evidence for an association between the new variant form of $\mathrm{ASD}^{58,59,65}$ and MMR vaccine, and between measles infection and autism, ${ }^{61,67}$ was also lacking.

\section{Thimerosal-containing vaccines and immune globulins}

Thimerosal, a preservative that contains $50 \%$ ethylmercury and is used for multivial vaccines such as the diptheria-tetanus-pertussis vaccine, has been widely researched because of concerns about mercury overexposure stemming from the expansion of childhood vaccination schedules in the past several decades. Thimerosal in Rh immune globulins given to pregnant women with Rh incompatibility issues has also been investigated as a source of prenatal mercury exposure.

\section{Postnatal thimerosal exposure: early childhood vaccines}

Seven studies demonstrated no significant association between thimerosal-containing childhood vaccines and ASD, ${ }^{68-74}$ while four studies did. ${ }^{66,75-77}$ However, most of the studies that supported an association, which all came from the same authors, did not control for potential confounders such as the child's age and sex, in contrast to most studies that found a null association. Both cohort studies that found significant positive associations used the Vaccine Adverse Events Reporting System database, which has been criticized as potentially biased and unreliable because anyone can report an adverse event after vaccination and diagnoses are not medically validated. ${ }^{78}$ Furthermore, no association has been found between autoimmune markers and autism in children given thimerosal-containing vaccines. ${ }^{79,80}$

\section{Prenatal thimerosal exposure: $R \mathbf{h}$ anti-D immune globulin}

Some studies, mostly larger case-control studies, refuted the association between maternal prenatal exposure to thimerosalcontaining Rh immune globulin and ASD, adjusting for maternal and/or birth characteristics, ${ }^{37,69,81,82}$ while others found significant 


\section{FIGURE 3}

Final selection of articles on associations between environmental factors and autism spectrum disorder, by subject and time period, 2003-2008 and 2009-2013

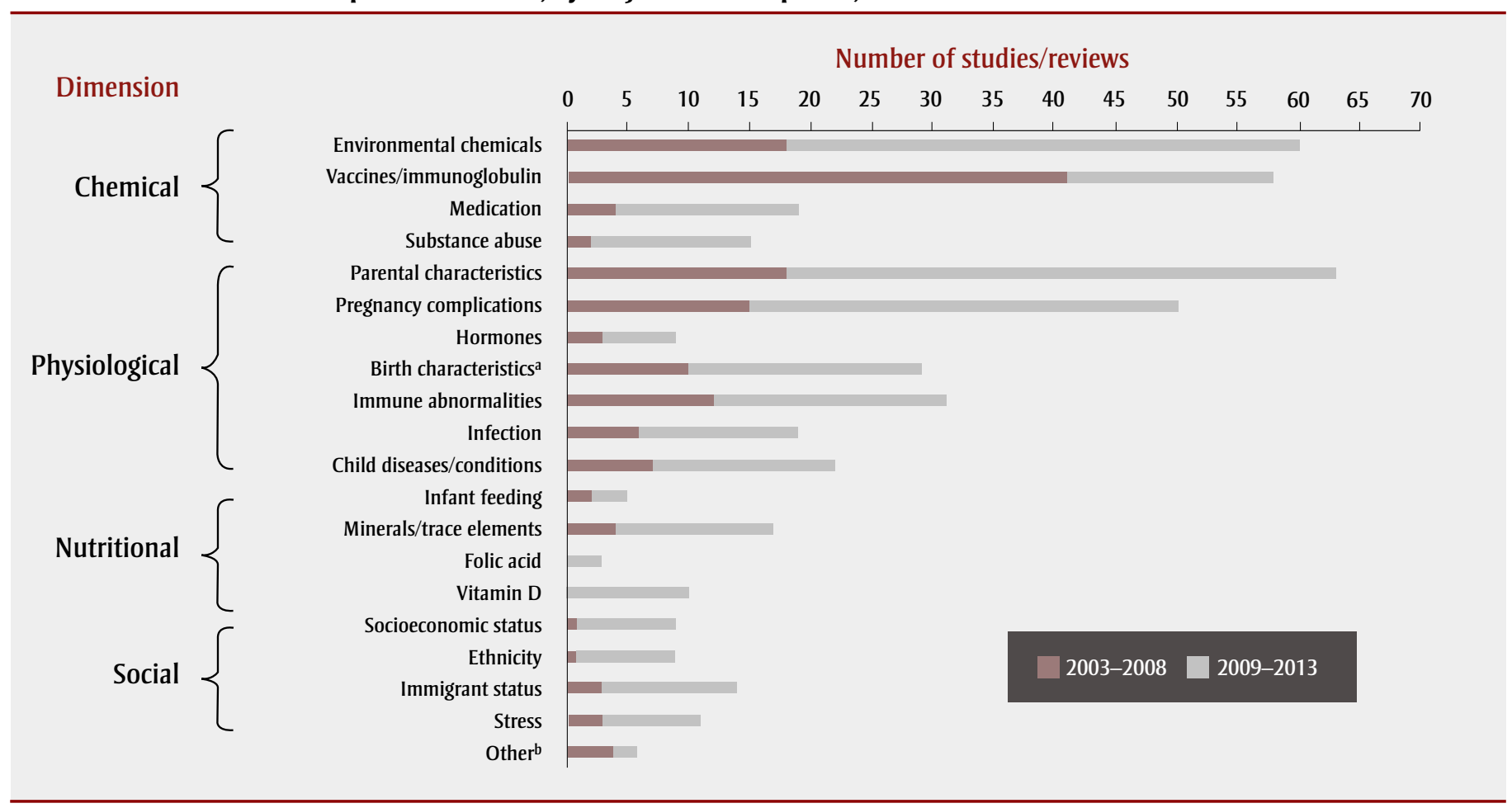

${ }^{\mathrm{a}}$ Includes birth order/parity, spacing, seasonality and multiple births.

${ }^{\mathrm{b}}$ Includes prenatal ultrasound, electromagnetic radiation and geographical clustering.

associations without adjusting for potential confounders. ${ }^{83,84}$

\section{Medication}

The increasing use of antidepressants, antibiotics $^{85}$ and acetaminophen ${ }^{86}$ has sparked hypotheses of possible links with the use of these medications and synchronous rising ASD prevalence in the 1980s.

Research on selective serotonin reuptake inhibitors (SSRIs; a class of antidepressants) in relation to ASD has emerged recently, with reviews indicating biologically plausible evidence of an association from animal and preclinical studies. ${ }^{87,88}$ Two case-control studies found a moderate association between prenatal use of SSRIs and ASD. ${ }^{89,90}$ However, if the relationship was causal, prenatal antidepressant use would account for fewer than $1 \%$ of ASD cases. ${ }^{90}$

Three reviews cited several clinical studies that provided evidence for increased ASD prevalence among children exposed to valproic acid (or valproate), a teratogenic broad spectrum antiepileptic drug and mood stabilizer, in early pregnancy compared to unexposed children..$^{91-93}$ Additionally, a large prospective cohort study showed that prenatal valproate exposure was associated with an absolute risk of ASD of $4.42 \%$ over a 14 -year period among those exposed. ${ }^{94}$

Some studies suggested a possible link between prenatal or early-life antibiotic use and autism..$^{85,95,96}$ Studies found ecological associations with prenatal use of acetaminophen ${ }^{97}$ and circumcision rate (a proxy for acetaminophen, which was widely used following circumcision), ${ }^{97}$ and an association with acetaminophen use following MMR vaccination. ${ }^{98}$ Biologically plausible mechanisms related to the endocannabinoid system affecting central nervous system (CNS) development ${ }^{98,99}$ or impaired detoxification ability upon overdose $^{86}$ have been suggested.

\section{Substance use}

\section{Tobacco smoke}

A meta-analysis has indicated no significant association between smoking during pregnancy and ASD. ${ }^{100}$ Likewise, no association was found in later studies. ${ }^{101-105}$ However, an association between maternal smoking during pregnancy and subclassifications of ASD, including Asperger syndrome and/or PDD-NOS, has been demonstrated. ${ }^{106-108}$ Maternal secondhand tobacco exposure may be associated with ASD or autism in children based on two small case-control studies. ${ }^{37,109}$

\section{Alcohol}

Two studies, including a prospective cohort study, found no association between prenatal alcohol consumption and ASD or autism, ${ }^{106,110}$ whereas a significant association with heavy prenatal consumption was evident in a small clinic sample. ${ }^{11}$

\section{Physiological dimension}

The physiological dimension encompasses many recurring themes related to the physiology of the parents and the child with ASD. Parental characteristics, particularly parental age, and pregnancy complications, especially low birth weight and prematurity, have been the most-studied risk factors for ASD (Table 5).

\section{Parental characteristics \\ Parental age}

Five systematic reviews supported the association between advanced parental 
TABLE 2

Chemical factors studied from 2003-2013 in association with autism spectrum disorder, by article type and subtheme

\begin{tabular}{|c|c|c|}
\hline Subtheme & $\begin{array}{c}\text { \# of } \\
\text { studies }\end{array}$ & $\begin{array}{l}\# \text { of } \\
\text { reviews }\end{array}$ \\
\hline Environmental chemicals & & $1^{\mathrm{a}}$ \\
\hline \multicolumn{3}{|l|}{ Heavy metals } \\
\hline Mercury & $31^{\mathrm{b}}$ & $13^{c}$ \\
\hline Other heavy metals & 15 & 6 \\
\hline \multicolumn{3}{|l|}{ Pollutants } \\
\hline Air & 5 & 1 \\
\hline Water & 2 & 0 \\
\hline $\begin{array}{l}\text { Occupational } \\
\text { chemicals }\end{array}$ & 2 & 0 \\
\hline Pesticides & 2 & 3 \\
\hline \multicolumn{3}{|l|}{ Vaccines/medication } \\
\hline MMR vaccine & $13^{\mathrm{d}}$ & 19 \\
\hline $\begin{array}{l}\text { Thimerosal-containing } \\
\text { vaccines/lg }\end{array}$ & $17^{\mathrm{e}}$ & 16 \\
\hline Other vaccine-related ${ }^{f}$ & 2 & 0 \\
\hline Valproate & 1 & 4 \\
\hline Antibiotics & 3 & 1 \\
\hline Acetaminophen & 2 & 4 \\
\hline Terbutaline & 1 & 0 \\
\hline Antidepressants & 2 & 2 \\
\hline \multicolumn{3}{|l|}{ Substance abuse } \\
\hline Alcohol & 3 & 0 \\
\hline Tobacco smoke & 10 & 3 \\
\hline
\end{tabular}

Abbreviations: ASD, autism spectrum disorder; MMR, measles, mumps, rubella; Ig, immune globulin.

Note: Some research articles may have multiple study designs and some studies may have examined multiple exposures; there may be overlap between subthemes.

a Review examines environmental chemicals as a whole and does not distinguish between different kinds.

${ }^{b}$ Excludes two studies that re-analyzed data from previously existing published research.

c One systematic review examined mercury exposure in general which ultimately included studies on thimerosal exposure.

d Two studies assessed association with measles virus infection.

${ }^{\mathrm{e}}$ Four studies on prenatal exposure to thimerosal through $\mathrm{Rh}$ immunoglobulin, 12 studies on postnatal exposure to thimerosal through child vaccines, and one study on both prenatal and postnatal exposure to thimerosal.

${ }^{f}$ Studies on exposure to aluminum adjuvant, fever following vaccine and mitochondrial disease, and adverse reactions following vaccine. age and ASD. ${ }^{13,100,112-114}$ A 2011 meta-analysis found a pooled odds ratio (OR) for autism of 1.78 (95\% confidence interval [CI]: 1.52-2.07) for fathers 40 to 49 years of age compared with fathers aged 29 years or younger. ${ }^{113}$ Since the latest systematic review, ${ }^{13}$ four studies have found a significant association with ASD or autism, ${ }^{115-118}$ whereas one did not. ${ }^{119}$ De novo mutations and genomic copy number variations burden have been implicated as possible underlying mechanisms, because they increase with paternal age. ${ }^{120,121}$ No association has been found between men with autistic-like traits and delayed parenting. ${ }^{122,123}$

A 2012 meta-analysis found the relative risk (RR) of ASD for mothers aged 35 years or over compared to those aged 25 to 29 years to be 1.31 ( $95 \%$ CI: 1.19 1.45). ${ }^{114}$ Since the most recent systematic review, ${ }^{114}$ four studies have found significant associations between advanced maternal age and $\mathrm{ASD}^{117,118,124,125}$ and one did not. ${ }^{106}$

Some studies have found paternal and maternal ages to be independent risk factors for ASD after adjusting for spousal age, ${ }^{126-128}$ and no evidence for a synergistic effect. ${ }^{117}$ Other studies have accounted for multicollinearity of maternal and paternal ages and found that advanced maternal age was the primary independent contributor of the parental age effect. ${ }^{18,129,130}$

\section{Assisted conception}

Assisted conception and ASD share risk factors such as high parental age, high rate of prematurity and low birth weight. ${ }^{131}$ A systematic review cited methodological limitations as the source of inconsistent findings for the association between assisted conception and ASD. ${ }^{132}$ Since then, two studies have found a positive association between assisted reproductive technology use and ASD, ${ }^{133,134}$ whereas five studies have found none. ${ }^{131,135-138}$ However, significant positive associations were found among subgroups such as women over age $34,{ }^{136}$ multiple births ${ }^{137}$ and those exposed to specific assisted conception methods. ${ }^{131,135}$

\section{Maternal chronic diseases and conditions}

Some evidence exists for associations between maternal chronic conditions such as weight gain, obesity and diabetes and ASD. Two ${ }^{109,139}$ of four studies found a positive association between maternal chronic conditions (aggregate measure) and ASD or autism. ${ }^{106,109,139,140} \mathrm{Two}^{141,142}$ of three cohort studies ${ }^{141-143}$ found a significant association between either prepregnancy weight, pregnancy weight gain or early-life obesity and ASD. A 2009 metaanalysis found a positive association between maternal gestational diabetes and ASD. ${ }^{100}$ Since then, there have been conflicting findings, ${ }^{102,124,139,141,144,145}$ although some of these studies did not differentiate between prepregnancy and gestational diabetes.

\section{Hormones}

Prenatal testosterone

An association between elevated prenatal testosterone levels and ASD or autism has been implicated in a review of three metaanalyses $^{146}$ and a case-control study. ${ }^{147}$ However, no significant correlation was found with neonatal testosterone levels in a cohort study. ${ }^{148}$

\section{Thyroid hormone}

Thyroid dysfunction, whether due to prenatal or early-life exposure to the antithyroid effects of heavy metals, to endocrine-disrupting chemicals or to dietary deficiencies, may affect neurodevelopment. ${ }^{149-151}$ However, evidence for the association between neonatal or maternal levels of thyroid hormone and ASD is limited and inconsistent. ${ }^{152-154}$

\section{Pregnancy complications}

A 2012 systematic review found perinatal and neonatal pregnancy complications to be significantly associated with ASD. ${ }^{13}$ However, findings were inconclusive for eclampsia and/or pregnancy-induced hypertension. Findings were also inconsistent among several other studies. ${ }^{102,103,124,125,145,155,156}$

\section{Birth weight and gestational age}

Two systematic reviews ${ }^{112,157}$ found low birth weight to be a significant risk factor for ASD in children; one of them, a metaanalysis, found a risk ratio (RR) of 1.63 (95\% CI: 1.19-2.33). ${ }^{157}$ However, a more recent systematic review ${ }^{13}$ indicated mixed findings. Since then, three ${ }^{158-160}$ of five studies ${ }^{106,109,158-160}$ have found a significant association between low birth weight and ASD. In most studies, the low birth weight threshold was $2500 \mathrm{~g}$.

Two $^{13,112}$ of three systematic reviews ${ }^{13,112,157}$ supported the association between low gestational age and ASD. Since the 2012 systematic review, ${ }^{13}$ most studies have provided more evidence for this 
TABLE 3

Associations of heavy metals in children with autism spectrum disorder or autism, found in studies and/or reviews published 2003-2013

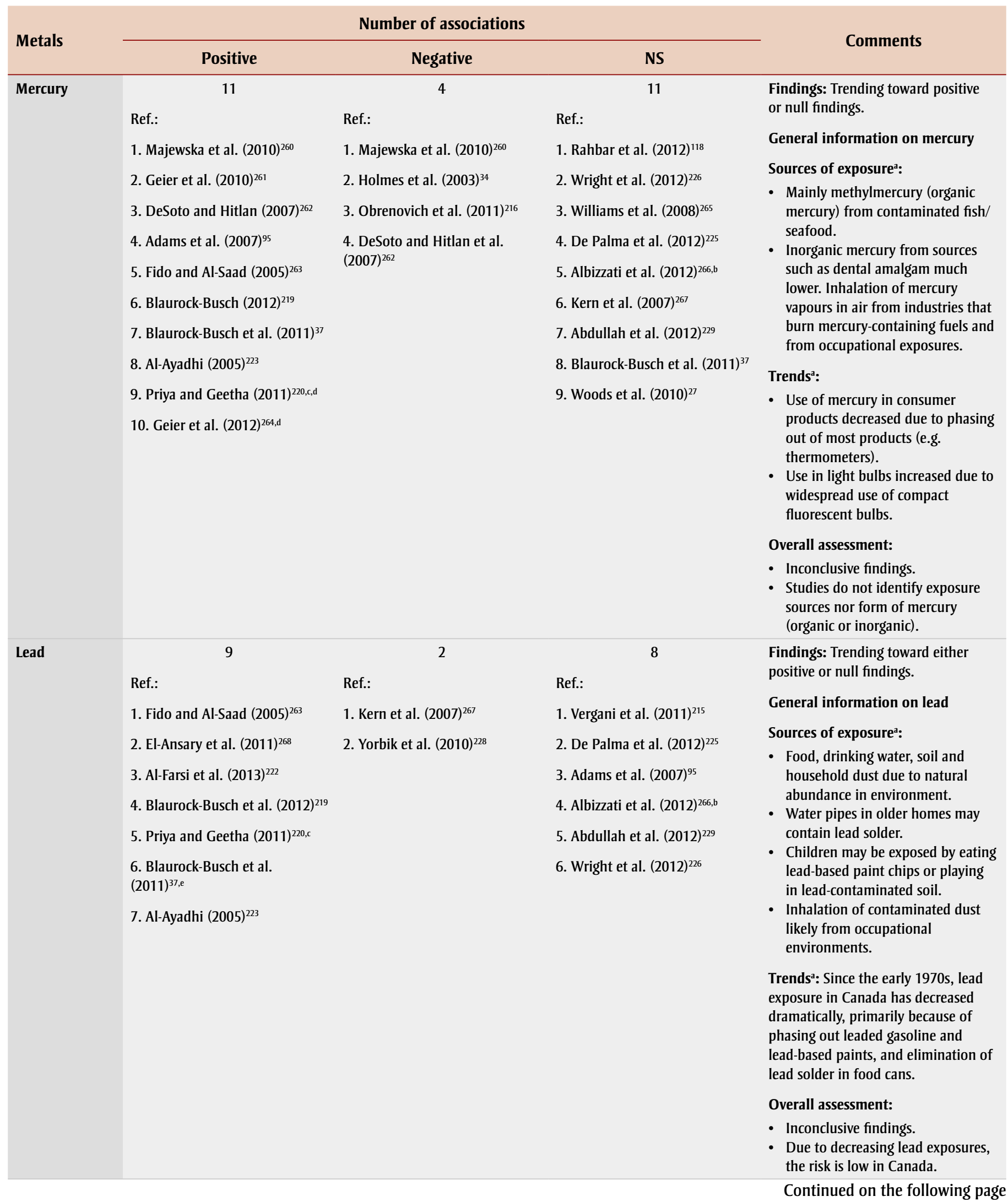


TABLE 3 (continued)

Associations of heavy metals in children with autism spectrum disorder or autism, found in studies and/or reviews published 2003-2013

\begin{tabular}{|c|c|c|c|c|}
\hline Metals & \multicolumn{3}{|c|}{ Number of associations } & Comments \\
\hline Cadmium & $\begin{array}{l}\text { Ref.: } \\
\text { 1. Vergani et al. }(2011)^{215} \\
\text { 2. Al-Farsi et al. }(2013)^{222} \\
\text { 3. Blaurock-Busch et al. }(2012)^{219} \\
\text { 4. Blaurock-Busch et al. }(2011)^{37} \\
\text { 5. Al-Ayadhi }(2005)^{223}\end{array}$ & $\begin{array}{l}\text { Ref.: } \\
\text { 1. Kern et al. }(2007)^{267} \\
\text { 2. Yorbik et al. }(2010)^{228}\end{array}$ & $\begin{array}{l}\text { Ref.: } \\
\text { 1. Albizzati et al. }(2012)^{266, b} \\
\text { 2. Fido and Al-Saad }(2005)^{263} \\
\text { 3. De Palma et al. }(2012)^{225} \\
\text { 4. Blaurock-Busch et al. }(2011)^{37} \\
\text { 5. Wright et al. }(2012)^{226}\end{array}$ & $\begin{array}{l}\text { Findings: Trending toward either } \\
\text { positive or null findings. } \\
\text { General information on cadmium } \\
\text { Sources of exposurea: } \\
\text { - Mainly food (e.g. leafy vegetables, } \\
\text { grains) and occupational sources. } \\
\text { Exposure to cadmium is low in all } \\
\text { foods. } \\
\text { - Drinking water and consumer } \\
\text { products (e.g. batteries, plastics) in } \\
\text { minor amounts. } \\
\text { - Cigarette smoke is a major source } \\
\text { for smokers. } \\
\text { Overall assessment: } \\
\text { - Inconclusive findings. } \\
\text { - Smokers at higher risk of exposure. } \\
\text { - Inorganic cadmium is associated } \\
\text { with lung cancer, severe gastroin- } \\
\text { testinal irritation and kidney } \\
\text { problems at high levels. } \\
\text { - Studies do not identify exposure } \\
\text { sources or form of cadmium. }\end{array}$ \\
\hline Aluminum & $\begin{array}{l}\text { Ref.: } \\
\text { 1. Blaurock-Busch et al. }(2011)^{37} \\
\text { 2. Blaurock-Busch et al. }(2012)^{219} \\
\text { 3. Al-Farsi et al. }(2013)^{222}\end{array}$ & 0 & $\begin{array}{l}\text { Ref.: } \\
\text { 1. Blaurock-Busch et al. }(2011)^{37} \\
\text { 2. Fido et al. }(2005)^{263} \\
\text { 3. Albizzati et al. }(2012)^{266, \mathrm{~b}} \\
\text { 4. Al-Ayadhi et al. }(2005)^{223} \\
\text { 5. Vergani et al. }(2011)^{215} \\
\text { 6. De Palma et al. }(2012)^{225}\end{array}$ & $\begin{array}{l}\text { Findings: No significant association } \\
\text { with aluminum in most studies. } \\
\text { General information on aluminum } \\
\text { Sources of exposurea: } \\
\text { - Mainly from food and oral intake } \\
\text { of medication containing } \\
\text { aluminum (e.g. antacids). Average } \\
\text { adult consumes 7-9 mg aluminum } \\
\text { per day in food. } \\
\text { - Inhalation and dermal contact } \\
\text { contribute small amount of daily } \\
\text { exposure. } \\
\text { - Exposure to small amounts of } \\
\text { aluminum from vaccinations. } \\
\text { - High level of exposure to } \\
\text { aluminum (likely occupational } \\
\text { source) may result in respiratory } \\
\text { and neurological problems. } \\
\text { Overall assessment: Likely no } \\
\text { association between aluminum and ASD. }\end{array}$ \\
\hline
\end{tabular}

Continued on the following page

association $^{145,159,161-163}$ although two studies did not. ${ }^{106,125}$ Based on the positive studies and the systematic review, ${ }^{13}$ the effect estimates for ASD or autism ranged from 1.4 to 4.7. The 37-week cut-off to define "preterm" births and the 32-week cut-off to define "extremely preterm" births were used in many studies.

Systematic reviews ${ }^{13,157}$ along with subsequent studies ${ }^{159,164}$ have also found a significant association between small for gestational age and ASD. Other studies have suggested that a deviance in fetal growth $^{165}$ and physical development ${ }^{140}$ may be associated with ASD onset.

\section{Clustering of pregnancy complications}

Eleven studies, including four cohort studies, found clustering of pregnancy complications to be significantly associated with ASD, ${ }^{102,104,106,109,124,141,143,166-169}$ and only one case-control study did not. ${ }^{140}$ Four systematic reviews also supported this association, ${ }^{13,100,112,157}$ with a general consensus that the presence of multiple factors is associated with ASD. However, the types of pregnancy complications examined vary by study. Many studies have explored the association between optimality scores (composite measures of compromised prenatal, perinatal and neonatal health overall) and ASD. Systematic reviews ${ }^{100,157}$ 
TABLE 3 (continued)

Associations of heavy metals in children with autism spectrum disorder or autism, found in studies and/or reviews published 2003-2013

\begin{tabular}{|c|c|c|c|c|}
\hline Metals & \multicolumn{3}{|c|}{ Number of associations } & Comments \\
\hline Arsenic & $\begin{array}{l}\text { Ref.: } \\
\text { 1. Al-Ayadhi }(2005)^{223} \\
\text { 2. Blaurock-Busch et al. }(2011)^{37} \\
\text { 3. Blaurock-Busch et al. }(2012)^{219} \\
\text { 4. Obrenovich et al. }(2011)^{216} \\
\text { 5. Vergani et al. }(2011)^{215}\end{array}$ & $\begin{array}{l}\text { Ref.: } \\
\text { 1. Kern et al. }(2007)^{267}\end{array}$ & $\begin{array}{l}\text { Ref.: } \\
\text { 1. Blaurock-Busch et al. }(2011)^{37} \\
\text { 2. Fido and Al-Saad }(2005)^{263} \\
\text { 3. De Palma et al. }(2012)^{225}\end{array}$ & $\begin{array}{l}\text { Findings: Most study samples found } \\
\text { positive association although inconsis- } \\
\text { tencies exist. } \\
\text { General information on arsenic } \\
\text { Sources of exposuree. } \\
\text { - Mainly from food (e.g. meat and } \\
\text { fish), but also from drinking water, } \\
\text { soil, air, and household dust, } \\
\text { although exposure usually low. } \\
\text { - Drinking water may be a major } \\
\text { source for populations living near } \\
\text { arsenic source. } \\
\text { - Arsenic present in cigarettes, } \\
\text { although exposure minor. } \\
\text { - High-level exposures usually } \\
\text { occupational, near hazardous } \\
\text { waste sites, or areas with high } \\
\text { natural levels. } \\
\text { Overall assessment: } \\
\text { - Inconclusive findings. } \\
\text { - High-level inorganic arsenic } \\
\text { exposure is a health concern. } \\
\text { Long-term exposure is of } \\
\text { carcinogenic potential. } \\
\text { - Form of arsenic detected in these } \\
\text { studies unknown. }\end{array}$ \\
\hline
\end{tabular}

Abbreviations: NS, not significant; Ref., references.

Note: Studies may examine associations with different heavy metals and/or specimens.

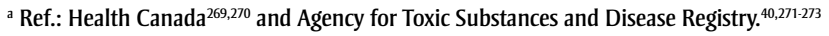

${ }^{\mathrm{b}}$ Blood, urine and hair tested with same results.

${ }^{\mathrm{C}} \mathrm{Hair}$ and nails tested with same results.

${ }^{\mathrm{d}}$ Indicates an association with ASD severity.

${ }^{\mathrm{e}}$ Urine and hair tested with same results.

have found that reduced prenatal and neonatal optimality is more evident than perinatal suboptimality in ASD cases. However, since those reviews, a prospective cohort study has found that having at least four obstetric suboptimality factors (mainly prenatal and perinatal) in the first birth were significantly correlated with ASD. ${ }^{124}$ Three other studies have found that suboptimal birth conditions ${ }^{101,105,141}$ and/or prenatal pregnancy complications ${ }^{102,106,141}$ were more common in children with ASD than in children without ASD.

Systematic reviews ${ }^{112,157}$ have implicated fetal hypoxia (intrauterine deprivation of oxygen) in ASD etiology, based on several perinatal factors that may serve as markers of hypoxia, including low Apgar score, caesarean section and growth retardation. However, fetal hypoxia has been weakly associated with ASD according to a population-based cohort study. ${ }^{170}$

\section{Birth characteristics}

\section{Birth order and spacing}

Systematic reviews agree that first-born children are more likely to be diagnosed with ASD than children born third or later; ${ }^{13,100}$ the meta-analysis found a $61 \%$ increased risk of autism for first-born children compared to children born third or later. ${ }^{100}$ This is also consistent with more recent studies, ${ }^{106,140,171,172}$ one of which investigated only Asperger patients. ${ }^{171}$ Suboptimal parity (giving birth more than two times) has been associated with ASD. ${ }^{124}$ Earlier birth order and greater parity appear to be conflicting risk factors, because first-born children in sibship sizes of two, and later-born children in families with larger sibship sizes, are more likely to have ASD. ${ }^{100}$ In addition, some studies have indicated that ASD symptom severity may be related to birth order, although these studies did not agree on which place in the birth order was more associated with severe symptoms, ${ }^{173,174}$ possibly because interpregnancy intervals may also be a factor. ${ }^{174}$ Interpregnancy intervals of less than 18 months $^{141}$ or less than a year have also been associated with autism in the second-born child. ${ }^{175}$

\section{Other birth characteristics}

Multiple births have been associated with ASD according to a meta-analysis ${ }^{157}$ as 
TABLE 4

Associations of prenatal, perinatal or postnatal exposure to air pollutants in children with autism spectrum disorder or autism, found in studies published 2003-2013

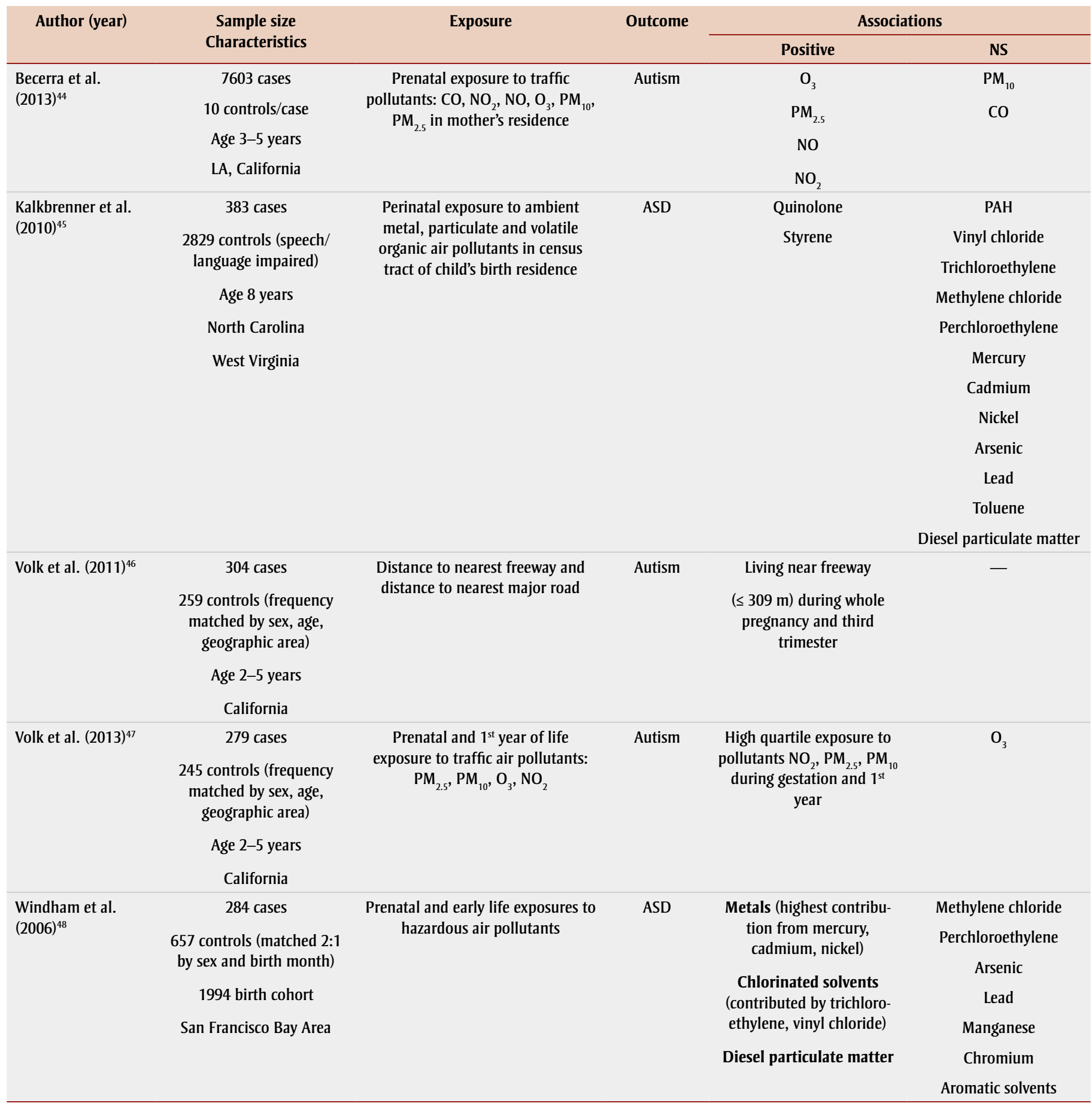

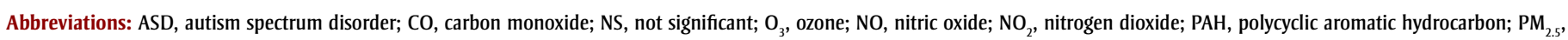
particulate matter $<2.5 \mu \mathrm{m} ; \mathrm{PM}_{10}$, particulate matter $<10 \mu \mathrm{m}$.

well as a cohort study, ${ }^{176}$ whereas an ecological study did not find an association. ${ }^{177}$ A meta-analysis also found a significant association between summer births and ASD. ${ }^{157}$ However, conflicting findings are evident in several studies. ${ }^{144,178-181}$

\section{Immune abnormalities}

According to a review of research trends, immune dysregulation has been widely studied and possesses the strongest evidence base of the physiological abnormalities in ASD. ${ }^{12}$ Early evidence found a potential link between ASD and two main types of immune dysfunction: autoimmunity and brain inflammation. ${ }^{182}$ In addition, significantly reduced neonatal blood immunoglobulin $\mathrm{G}$ has been observed in archived specimens from newborns subsequently diagnosed with ASD relative to 
TABLE 5

Physiological factors studied from 20032013 in association with autism spectrum disorder, by article type and subtheme

\begin{tabular}{|c|c|c|}
\hline Subtheme & $\begin{array}{l}\text { \# of } \\
\text { studies }\end{array}$ & $\begin{array}{l}\text { \# of } \\
\text { reviews }\end{array}$ \\
\hline \multicolumn{3}{|l|}{ Parental characteristics } \\
\hline Parental age & 39 & 7 \\
\hline Assisted conception & 8 & 1 \\
\hline $\begin{array}{l}\text { Maternal chronic } \\
\text { conditions: }\end{array}$ & 16 & 2 \\
\hline Aggregate & 3 & 0 \\
\hline Diabetes $^{\mathrm{a}}$ & 10 & 2 \\
\hline $\begin{array}{l}\text { Weight/pregnancy } \\
\text { weight gain }\end{array}$ & 4 & 0 \\
\hline \multicolumn{3}{|l|}{$\begin{array}{l}\text { Pregnancy complica- } \\
\text { tions }\end{array}$} \\
\hline Low birth weight & 16 & 6 \\
\hline Low gestational age & 19 & 6 \\
\hline Post-term birth & 2 & 1 \\
\hline SGA or LGA & 6 & 2 \\
\hline Fetal growth ${ }^{\mathrm{b}}$ & 2 & 0 \\
\hline $\begin{array}{l}\text { Clustering of complica- } \\
\text { tions }\end{array}$ & 12 & 6 \\
\hline All complications & 39 & 11 \\
\hline \multicolumn{3}{|l|}{ Hormones } \\
\hline Testosterone & 2 & 1 \\
\hline Thyroid & 3 & 3 \\
\hline \multicolumn{3}{|l|}{ Birth characteristics } \\
\hline Birth order/spacing & 15 & 4 \\
\hline Multiple births & 3 & 1 \\
\hline Birth seasonality & 7 & 2 \\
\hline Immune abnormalities & & $1^{c}$ \\
\hline Autoimmune disease & 10 & 8 \\
\hline Brain inflammation & 5 & 10 \\
\hline Other & 1 & 0 \\
\hline Infection & 14 & 5 \\
\hline \multicolumn{3}{|l|}{$\begin{array}{l}\text { Associated child } \\
\text { diseases/conditions }\end{array}$} \\
\hline Neonatal jaundice & 6 & 3 \\
\hline Epileptic disorders & 5 & 2 \\
\hline Oxidative stress & 6 & 2 \\
\hline
\end{tabular}

Abbreviations: GA, gestational age; LGA, large for gestational age; SGA, small for gestational age.

Note: There is some overlap of subthemes across different studies/reviews.

${ }^{\text {a }}$ Prepregnancy and/or gestational diabetes.

${ }^{\mathrm{b}}$ Composite measure of birth weight and GA; head circumference in low-birth-weight and GA children.

c Review does not distinguish between different immune abnormalities. newborns not subsequently diagnosed with ASD. ${ }^{183}$

\section{Autoimmune diseases}

Several studies have examined the role of autoimmunity in ASD. Three case-control studies have consistently demonstrated that antibody reactivity to human fetal brain protein is more prevalent in mothers of children with ASD or specifically autism than in mothers of children who do not have ASD or specifically autism. ${ }^{184-186}$ Additionally, there may be increased serum folate receptor autoantibodies in children with low-functioning autism with or without neurological deficits relative to control subjects without autism. ${ }^{187}$ This suggests that folate transfer to the fetus during pregnancy may be blocked, which may increase risk of neural tube defects. ${ }^{188}$ Because these elevated autoantibodies were also present in at least one parent of children with autism, parental antibodies may contribute to autism etiology. ${ }^{189}$

Two cohort studies and a case-control study found an association between maternal or family history of autoimmune diseases and $\mathrm{ASD}^{124,190}$ or autistic regression, ${ }^{191}$ whereas another case-control study found no association. ${ }^{192}$ However, the specific autoimmune diseases associated with ASD varied by study. Reviews have discussed growing evidence for the role of autoimmunity in ASD, stemming mostly from animal models and human clinical studies, but have indicated a need to identify the functions of the autoantibodies that might be affecting neurodevelopment. ${ }^{193-196}$

\section{Brain inflammation}

Brain inflammation has also been implicated in the etiology of ASD. According to the reviews based mainly on animal and human clinical studies, early-life immune insults such as toxic substances, food additives or stress may result in a cascade of excitotoxicity in the brain, ${ }^{197-199}$ and may be related to dysregulation of glutamate neurotransmission. ${ }^{199,200}$ This cascade may trigger production of proinflammatory cytokines, resulting in chronic inflammation affecting neurodevelopment.

Emerging evidence, mostly from case-control studies, has shown that increased proinflammatory cytokine production is found in the serum or cerebrospinal fluid of ASD children or the amniotic fluid of their mothers, ${ }^{201-203}$ although a decreased neonatal level of cytokines has also been observed. ${ }^{204}$ Significantly altered adaptive cellular immune function in children with ASD may reflect defective immune activation, which may in turn be associated with ASD impairment. ${ }^{203}$ Also, no significant differences have been reported for levels of certain chemokines in neonatal blood and amniotic fluid, ${ }^{201,205}$ except in a subgroup with an ASD diagnosis based on the most recent diagnostic criteria. ${ }^{201}$

\section{Infection}

Infections may trigger the chronic inflammation of the CNS, affecting brain development and maturation, which has been implicated in ASD etiology. ${ }^{198}$ However, according to a meta-analysis ${ }^{100}$ and 2012 literature review, ${ }^{206}$ there was no significant association between maternal infection and ASD. A 2012 systematic review indicated that more research is required to explore this association. ${ }^{13}$ Since then, only one case-control study found a significant association, ${ }^{106}$ whereas one cohort and three case-control studies did not. ${ }^{96,125,140,207}$ The definition of maternal infection varies across studies; it may encompass any infection during pregnancy, or only specific infections such as influenza. ${ }^{207}$ Some studies have suggested maternal fever during pregnancy ${ }^{207}$ or extended febrile episodes $^{96}$ are associated with ASD, although findings are mixed. ${ }^{145,208}$

\section{Associated child diseases \\ Neonatal jaundice}

Neonatal jaundice, a result of elevated serum bilirubin levels (hyperbilirubinemia), has been a concern because unconjugated bilirubin can be toxic to the developing CNS. Five studies ${ }^{125,144,209-211}$ and two systematic reviews ${ }^{13,157}$ investigated this risk factor. According to the systematic reviews, hyperbilirubinemia was associated with an increased risk of autism ${ }^{13,157}$ with a summary effect estimate of 1.87 (95\% CI: 1.01-3.47), according to the meta-analysis. ${ }^{157}$

\section{Epileptic disorders}

While a meta-analysis indicated no significant relationship between neonatal seizures and ASD, ${ }^{157}$ four small studies have provided some evidence for a possible association. ${ }^{125,212-214}$

\section{Oxidative stress}

According to a review of research trends, oxidative stress was one of the moststudied physiological abnormalities in ASD, with one of the strongest evidence bases, mainly consisting of clinical and animal studies. ${ }^{12}$ Six case-control studies 
indicated a role for oxidative stress in ASD patients $^{29,30,215-218}$ based on different biomarkers of oxidative stress and impaired antioxidant systems. Biomarkers included altered levels of oxidative stress defence systems, including metallothioneins and antioxidant enzymes. ${ }^{215}$ Other markers of oxidative stress, associated heavy metal toxicity and/or low detoxification capacity included abnormal markers of thiol metabolism, ${ }^{216}$ transsulfuration abnormalities, ${ }^{30}$ urinary organic acids,,$^{29}$ and increased lead and potassium ions, ATPase activity and lipid peroxidation products. ${ }^{217}$

\section{Nutritional dimension}

Deficiencies in minerals and levels of trace elements were the most-studied of the nutritional factors in association with ASD, followed by vitamin D deficiency (Table 6).

\section{Minerals and trace elements}

Evidence for mineral deficiencies and levels of trace elements in children with ASD or specifically, autism, comes mainly from case-control studies examining hair samples and remains inconclusive. Studies looking at associations between levels of zinc, ${ }^{37,95,215,219-223}$ iron, ${ }^{37,215,216,219,222-224}$ magnesium, $37,219,220,222,223$ copper, ${ }^{37,215,216,219,220,222,223,225,226}$ molybdenum, ${ }^{37,219,222,223,225}$ nickel, ${ }^{215,219,222,223,225}$ and selenium ${ }^{37,219,220,223,225}$ and ASD have had conflicting results. Calcium deficiencies have also been documented in association with ASD or autism in children, ${ }^{219,222,223,227}$ with some inconsistencies..$^{37,215}$ Despite inconsistencies, differences in the levels of cobalt, ${ }^{37,215,222,223,225,226}$ chromium $^{37,215,222,223,225,228}$ and manganese $\mathrm{e}^{37,215,219,223,225,226,229}$ in children with and without ASD or autism were mostly nonsignificant.

TABLE 6

Nutritional factors studied from 2003-2013 in association with autism spectrum disorder, by article type and subtheme

\begin{tabular}{lcc} 
Subtheme & $\begin{array}{c}\text { \# of } \\
\text { studies }\end{array}$ & $\begin{array}{c}\text { \# of } \\
\text { reviews }\end{array}$ \\
\hline $\begin{array}{l}\text { Minerals/trace } \\
\text { elements }\end{array}$ & 16 & 2 \\
\hline Vitamin D & 5 & 5 \\
\hline Infant feeding & 3 & 2 \\
\hline Folic acid & 2 & 1 \\
\hline
\end{tabular}

Note: There is some overlap of subthemes across different studies/reviews.

\section{Vitamin D}

Vitamin D plays a crucial role in various functions, such as neurodevelopment, the anti-inflammatory response and the detoxification pathway. ${ }^{230,231}$ However, evidence for an association between vitamin D deficiency and ASD is limited and indirect. Two ecological studies ${ }^{63,232}$ and a case-control study ${ }^{227}$ have indicated an association between vitamin $\mathrm{D}$ deficiency in mothers and/or their children with autism, and the onset of autism. It has been suggested that migration may play a role in the etiology of ASD, because of increased autism prevalence rates among immigrants in northern European countries, and because immigrants with dark skin are more prone to vitamin D deficiency due to their skin pigmentation. ${ }^{233}$ However, both a small case-control study ${ }^{234}$ and a recent Australian prospective cohort study ${ }^{235}$ found no significant association between maternal serum vitamin D levels and ASD or a majority of autistic-like traits in their offspring. Furthermore, a systematic review concluded that there was inadequate support for an association, and that more population-based longitudinal studies are needed, given the plausible biological evidence. $^{230}$

\section{Infant feeding}

We found few studies on infant feeding methods in relation to ASD, although two case-control studies found that the absence or late initiation of breastfeeding was significantly associated with ASD or autism, ${ }^{236,237}$ in contrast to findings of an ecological study. ${ }^{63}$

\section{Folic acid}

Evidence supporting an association between folic acid intake and ASD is very sparse, although a recent prospective cohort study found maternal folic acid intake to be protective against $A S D, 238$ in contrast to an ecological study that found positive correlations between the percentages of prescription prenatal vitamins and pediatric vitamins containing folic acid and ASD incidence. ${ }^{239}$

\section{Social dimension}

Socioeconomic status (SES), ethnicity, immigrant status and stress were recurring social factors examined in association with ASD (Table 7).

\section{Socioeconomic status}

The importance of SES emerged as a predictor of ASD risk in nine studies, ${ }^{102,119,172,240-245}$ but findings were mixed. Mainly in American studies, a higher SES, using proxies such as maternal income, occupation and education, was associated with ASD. ${ }^{172,240-242}$ However, when researchers in one of these studies conducted a subanalysis by case ascertainment, no association with SES was found using case ascertainment only from school sources. ${ }^{242}$ In an Australian study, ${ }^{172}$ maternal residence in remote areas was negatively correlated with cases of ASD without intellectual disability (ID). However, other studies had different results. ${ }^{102,119,243,244}$ In countries with universal health care programs, such as Sweden and Canada, lower family or maternal income was associated with ASD, which suggests that the associations between high SES and ASD found mainly in the US studies may reflect inequalities in access to health care services (e.g. under-diagnosis of ASD in families with lower SES). ${ }^{102,244}$ Furthermore, spatial analysis of autism incidence in regions of California indicated a higher incidence that was independently characterized by higher levels of parental education. $^{245}$

\section{Ethnicity}

Most studies that examined the relationship between maternal ethnicity and ASD found a significant association, ${ }^{102,119,172,242,243,246}$ with the exception of one study in the United Kingdom. ${ }^{247}$ In particular, maternal minority ethnic status, such as Aboriginal status, was associated with reduced ASD diagnosis in offspring ${ }^{102,119,172,243}$ with an OR ranging from 0.33 to 0.83 for certain non-White ethnic groups compared to White, non-Hispanic people. Furthermore, children who were Black, Hispanic or

TABLE 7

Social factors studied from 2003-2013 in association with autism spectrum disorder, by article type and subtheme

\begin{tabular}{lcc} 
Subtheme & $\begin{array}{c}\text { \# of } \\
\text { studies }\end{array}$ & $\begin{array}{c}\text { \# of } \\
\text { reviews }\end{array}$ \\
\hline Socioeconomic status & 9 & 0 \\
\hline Ethnicity & $\mathbf{8}$ & $\mathbf{1}$ \\
\hline Immigrant status & 9 & 5 \\
\hline Stress & $\mathbf{8}$ & 3 \\
\hline
\end{tabular}

Note: There is some overlap of subthemes across different studies/reviews. 
“other" race/ethnicity were less likely than White children to have ASD, which was more pronounced in children with ID for some ethnic groups, according to an American study. ${ }^{246}$ The finding that minority groups would be less likely to be diagnosed with ASD may be due to ascertainment bias. Differential assessment of children's intellectual and developmental problems may account for these ethnic disparities. In contrast, another American study found that Black race was associated with increased odds of ASD, particularly with ID, but case ascertainment was more likely from school sources. ${ }^{242}$ These studies suggest possible racial or ethnic disparities in ASD diagnosis such that for some groups, comorbid ID may affect its detection.

\section{Immigrant status}

Maternal immigrant status is another social factor that emerged in eight studies $^{104,208,243,247-251}$ and two systematic reviews ${ }^{13,100}$ supporting an association with ASD or ASD subtype. Migrant mothers had a higher prevalence of offspring with ASD in studies from Sweden, the United Kingdom and Australia. The meta-analysis found a marginal association between maternal immigrant status and autism (summary effect estimate $=1.28$; $p=.06) .{ }^{100}$ However, among Nordic countries, the association was statistically significant, with a $58 \%$ increased risk among children whose mothers were born abroad. ${ }^{100}$ According to a Swedish study, migrant parents from countries with a low ranking on a human development index may be at increased risk of having children with ASD and comorbid ID compared with Swedish-born parents, particularly when migration occurred around time of pregnancy, suggesting a possible link with maternal stress. ${ }^{249}$ However, migrant parents from developing countries may have a decreased risk of having children with PDD-NOS or Asperger. ${ }^{250}$ Sociopolitical context such as changes in immigration policy has also been shown to influence trends in autism diagnosis rates. For example, a decline in autism rates among Hispanic children in the United States was attributed to undocumented immigrant parents' reluctance to seek diagnostic services due to fears of being reported to the authorities and having to face deportation when threatened by anti-immigrant policy enforcement. ${ }^{251}$

\section{Maternal stress}

Prenatal exposure to environmental stressors, including stress-related immunological and neuroinflammatory abnormalities and placental dysfunction that can affect fetal neurodevelopment, may play a role in ASD etiology. ${ }^{252,253}$ A 2012 systematic review indicated this association requires more study to provide conclusive evidence. ${ }^{13}$ Since then, one cohort study and a case-control study have shown that maternal stress during pregnancy is associated with conceiving a child with ASD, ${ }^{106,254}$ whereas three other case-control studies did not find an association. ${ }^{140,145,255}$ In many of these studies, "stressors" may be defined broadly as any type of stressful event, ${ }^{106,140,145,255}$ or specifically as certain stressful events such as early-life childhood abuse. ${ }^{254}$

\section{Other}

In addition to the chemical, physiological, nutritional and social dimensions, several other factors emerged that were investigated for association with ASD. Two studies showed that autism births occur in geographical clusters, which could indicate that local factors are involved in the prevalence. $^{247,256}$ Another study found that while electromagnetic radiation has been hypothesized to be a risk factor due to biological plausibility, no epidemiological evidence is yet available. ${ }^{257}$ Other studies have found no significant association between prenatal exposure to ultrasound and ASD. ${ }^{256,258}$

\section{Discussion}

Most of the research on the environmental contribution to ASD etiology focussed on physiological or chemical risk factors, and less on social and nutritional factors. Within these dimensions, however, the vast literature is riddled with inconsistent findings. Heterogeneity is evident in study populations, exposure and outcome assessment, changing diagnostic criteria and/or ASD phenotypes, all of which vary between studies and may affect the validity of findings.

Biomarkers of heavy metal exposure, particularly mercury, from levels measured in biological specimens such as hair, blood and urine have been studied intensely, but its association with ASD remains uncertain due to conflicting findings. Because most of these studies only measure biomarkers of heavy metal, and do not ascertain actual exposure sources, temporality of association is unknown. Furthermore, many of the biomarker studies had small sample sizes. These findings are consistent with a recent systematic review by Rossignol and colleagues ${ }^{11}$ (published in 2014, after the completion of our review), who examined the association between environmental toxicant exposure and ASD.

In contrast, emerging evidence for the association between traffic-related air pollutants and ASD or autism has been relatively consistent, although further research is required to establish specificity of association and improve external validity beyond the American landscape. These findings are also consistent with Rossignol's review, which found that air pollution is the chemical risk factor with the strongest evidence of an association with ASD, although the association with pesticides was also relatively strong.

Despite numerous studies exploring the relationship between MMR or thimerosalcontaining vaccines and ASD, there is a lack of convincing support for this association. Additionally, evidence of an association between fetal or childhood exposure to various medications and ASD is limited to a few studies. A lack of association between tobacco smoke exposure and ASD is also apparent, although some studies have indicated a possible link with PDD-NOS, warranting further study on ASD subgroups separately if causal relationships are to be elucidated. Moreover, studies on exposure to occupational chemicals, pesticides and alcohol were limited.

The most widely and consistently implicated physiological factors in ASD onset include advanced parental age, low birth weight, prematurity and clustering of pregnancy complications. A consistent association between hyperbilirubinemia and ASD has been demonstrated as well. More research is warranted on the effects of advanced grandparental age on ASD, based on preliminary findings. ${ }^{115,259}$ Furthermore, studies are needed to understand the mechanisms for associations between these physiological factors and ASD. Emerging epidemiological evidence for immune abnormalities related to autoimmunity and brain inflammation have also been reported in children with ASD or their mothers. However, further work is 
required to establish temporality of association and to elucidate their possible role in ASD etiology.

More research is also needed to understand other physiological factors such as birth characteristics, maternal chronic conditions, hormones and child conditions in relation to ASD. Studies have indicated a potential relationship between chronic conditions such as pregnancy weight gain or maternal diabetes and ASD. However, due to heterogeneity and lack of specificity of exposures, further research is warranted. Evidence for a link between earlier birth order, greater parity and short interpregnancy intervals and ASD exists, although the etiological contribution is not clear. The association between oxidative stress and ASD has been demonstrated by a limited number of small epidemiological studies.

The relationship between nutritional factors and ASD has not been well studied compared to that with chemical and physiological factors. Although several studies investigated associations with mineral and/or trace element deficiencies and vitamin D deficiency, evidence is inconsistent and indirect. For example, maternal foreign birthplace and/or ethnicity were used as proxies for vitamin D concentration, based on the possibly inaccurate assumption that women in these categories would have darker skin pigmentation, affecting their vitamin D concentrations. ${ }^{233}$ More direct evidence for an association between vitamin $\mathrm{D}$ and ASD by direct exposure measurements is required.

The current literature suggests that associations between social factors such as SES and ethnicity and ASD may vary across countries, depending on possible case ascertainment biases. However, maternal immigrant status has been consistently correlated with ASD. Whether this may relate to SES, adaptation to a new environment, stress or changes in vitamin $\mathrm{D}$ exposure as suggested by some studies requires further investigation.

Overall, the lack of consistency, temporality and specificity of the associations observed in many studies precludes the establishment of causality. Longitudinal studies may be helpful in establishing temporality to identify possible causal relationships. Consistent methods of measuring exposure and case ascertainment and consideration for potential confounders could reduce heterogeneity. Underlying mechanisms of some of these associations need to be investigated through further biological research.

\section{Strengths and limitations}

Of the reviews that have explored possible risk factors of ASD to date, none have examined the entire scope of the environmental contribution to ASD. We conducted a comprehensive, systematic search of the literature. Although all relevant articles may not have been retrieved in this review, a large number of potentially contributing factors were identified that can provide an adequate picture of the breadth of environmental contribution to ASD etiology.

Although the search strategy to retrieve relevant ASD articles aimed for comprehensiveness, key scientific journals were not hand-searched and no searches were performed on citations referenced in included studies and grey literature. Furthermore, more information on environmental factors may have been missed if articles covering them also dealt with animal models or genetic studies, which were excluded. This is evident for research in immune abnormalities and oxidative stress, because articles retrieved were fewer in number although reviews have indicated a vast amount of research, likely from clinical and animal studies. Because the aim of this scoping review was to assess the current state of knowledge of environmental risk factors of ASD, quality assessment of these studies was not performed to assess the strength of evidence.

\section{Conclusion}

Our scoping review examined research conducted between 2003 and 2013 on environmental factors potentially associated with ASD, grouped into four categories: chemical, physiological, nutritional and social. We found that physiological factors including advanced parental age, low birth weight, prematurity, hyperbilirubinemia and clustering of pregnancy complications have been consistently reported as risk factors for ASD. While evidence for an association with traffic-related air pollutants is emerging, research on nutritional factors associated with ASD is limited. Of the factors in the social dimension, immigrant status has been consistently associated with ASD, which warrants further research. Other associations with social factors such as SES and ethnicity may reflect disparities in ASD diagnosis. Large prospective studies, adjusting for sociodemographic confounders, are needed to resolve inconsistencies, especially in the area of heavy metal exposure, where evidence for an association with ASD is still inconclusive.

Because there are a variety of associations with ASD, the etiology is likely multifactorial. Future studies should continue exploring how these different factors may be interrelated. Overall, the lack of consistency, temporality and specificity of associations between environmental factors and ASD remains the largest barrier to establishing causal relationships.

\section{References}

1. American Psychiatric Association. Diagnostic and Statistical Manual of Mental Disorders: DSM-IV-TR. Washington, DC: American Psychiatric Association; 2000.

2. Boyle CA, Boulet S, Schieve LA, Cohen RA, Blumberg SJ, YearginAllsopp M, et al. Trends in the prevalence of developmental disabilities in US children, 1997-2008. Pediatrics. 2011;127(6):1034-1042.

3. Centers for Disease Control and Prevention (CDC). Prevalence of autism spectrum disorder among children aged 8 years - Autism and Developmental Disabilities Monitoring Network, 11 sites, United States, 2010. Surveillance Summaries. MMWR. 2014; 63(SS02):1-21.

4. National Epidemiologic Database for the Study of Autism in Canada (NEDSAC). Estimated prevalence of autism spectrum disorders among children 2-14 years of age in three Canadian regions (2003-2010) [Internet]. Kingston (ON): NEDSAC; 2012 [cited 2014 March 1]. Available from: http://www.nedsac.ca/sites /webpublish.queensu.ca.nedwww /files/files/Table_Prevalence _2003to2010.pdf

5. Rutter M. Incidence of autism spectrum disorders: changes over time and their meaning. Acta Paediatr. 2005; 94(1):2-15. 
6. King $M$, Bearman P. Diagnostic change and the increased prevalence of autism. Int J Epidemiol. 2009;38(5): 1224-1234.

7. Hertz-Picciotto I, Delwiche L. The rise in autism and the role of age at diagnosis. Epidemiology. 2009;20(1): 84-90.

8. Hallmayer J, Cleveland S, Torres A, Phillips J, Cohen B, Torigoe $\mathrm{T}$, et al. Genetic heritability and shared environmental factors among twin pairs with autism. Arch Gen Psychiatry. 2011;68(11):1095-1102.

9. Wigle DT, Arbuckle TE, Walker M, Wade MG, Liu S, Krewski D. Environmental hazards: evidence for effects on child health. J Toxicol Environ Health B Crit Rev. 2007; 10(1-2):3-39.

10. Currenti SA. Understanding and determining the etiology of autism. Cell Mol Neurobiol. 2010;30(2):161-171.

11. Rossignol DA, Genuis SJ, Frye RE. Environmental toxicants and autism spectrum disorders: a systematic review. Transl Psychiatry. 2014;4:e360.

12. Rossignol DA, Frye RE. A review of research trends in physiological abnormalities in autism spectrum disorders: immune dysregulation, inflammation, oxidative stress, mitochondrial dysfunction and environmental toxicant exposures. Mol Psychiatry. 2012;17(4):389-401.

13. Guinchat V, Thorsen P, Laurent C, Cans C, Bodeau N, Cohen D. Pre-, peri- and neonatal risk factors for autism. Acta Obstet Gynecol Scand. 2012;91(3):287-300.

14. Landrigan PJ. What causes autism? Exploring the environmental contribution. Curr Opin Pediatr. 2010;22(2): 219-225.

15. Curtis LT, Patel K. Nutritional and environmental approaches to preventing and treating autism and attention deficit hyperactivity disorder (ADHD): a review. J Altern Complement Med. 2008;14(1):79-85.

16. Hughes JR. Update on autism: a review of 1300 reports published in 2008. Epilepsy Behav. 2009;16(4): 569-589.
17. Daudt HM, van Mossel C, Scott SJ. Enhancing the scoping study methodology: a large, inter-professional team's experience with Arksey and O’Malley's framework. BMC Med Res Methodol. 2013;13:48.

18. Windham GC, Sumner A, Li SX, et al. Use of birth certificates to examine maternal occupational exposures and autism spectrum disorders in offspring. Autism Res. 2013;6(1):57-63.

19. McCanlies EC, Fekedulegn D, Mnatsakanova A, Burchfiel CM, Sanderson WT, Charles LE, et al. Parental occupational exposures and autism spectrum disorder. J Autism Dev Disord. 2012;42(11):2323-2334.

20. Roberts EM, English PB, Grether JK, Windham GC, Somberg L, Wolff C. Maternal residence near agricultural pesticide applications and autism spectrum disorders among children in the California Central Valley. Environ Health Perspect. 2007;115(10):1482-1489.

21. Shelton JF, Hertz-Picciotto I, Pessah IN. Tipping the balance of autism risk: potential mechanisms linking pesticides and autism. Environ Health Perspect. 2012;120(7):944-951.

22. Ash MM, Nelson SJ. Wheeler's dental anatomy, physiology and occlusion. 8th ed. St. Louis: Elsevier; 2003.

23. Bernard S, Enayati A, Redwood L, Roger H, Binstock T. Autism: a novel form of mercury poisoning. Med Hypotheses. 2001;56(4):462-471.

24. Woods JS, Martin MD, Naleway CA, Echeverria D. Urinary porphyrin profiles as a biomarker of mercury exposure: studies on dentists with occupational exposure to mercury vapor. J Toxicol Environ Health. 1993;40(2-3):235-246.

25. Nataf R, Skorupka C, Amet L, Lam A, Springbett A, Lathe R. Porphyrinuria in childhood autistic disorder: implications for environmental toxicity. Toxicol Appl Pharmacol. 2006;214(2): 99-108.

26. Geier DA, Geier MR. A prospective assessment of porphyrins in autistic disorders: a potential marker for heavy metal exposure. Neurotox Res. 2006;10(1):57-64.
27. Woods JS, Armel SE, Fulton DI, et al. Urinary porphyrin excretion in neurotypical and autistic children. Environ Health Perspect. 2010;118(10):1450-1457.

28. Austin DW, Shandley K. An investigation of porphyrinuria in Australian children with autism. J Toxicol Environ Health A. 2008;71(20): 1349-1351.

29. Youn SI, Jin SH, Kim SH, Lim S. Porphyrinuria in Korean children with autism: correlation with oxidative stress. J Toxicol Environ Health A. 2010;73(10):701-710.

30. Geier DA, Kern JK, Garver CR, et al. Biomarkers of environmental toxicity and susceptibility in autism. J Neurol Sci. 2009;280(1-2):101-108.

31. Kern JK, Geier DA, Adams JB, Geier MR. A biomarker of mercury body-burden correlated with diagnostic domain specific clinical symptoms of autism spectrum disorder. Biometals. 2010;23(6):1043-1051.

32. Palmer RF, Blanchard S, Stein Z, Mandell D, Miller C. Environmental mercury release, special education rates, and autism disorder: an ecological study of Texas. Health Place. 2006;12(2):203-209.

33. Palmer RF, Blanchard S, Wood R. Proximity to point sources of environmental mercury release as a predictor of autism prevalence. Health Place. 2009;15(1):18-24.

34. Holmes AS, Blaxill MF, Haley BE. Reduced levels of mercury in first baby haircuts of autistic children. Int J Toxicol. 2003;22(4):277-285.

35. Geier DA, Kern JK, Geier MR. A prospective study of prenatal mercury exposure from maternal dental amalgams and autism severity. Acta Neurobiol Exp (Wars). 2009;69(2): 189-197.

36. Rahbar MH, Samms-Vaughan $M$, Loveland KA, Ardjomand-Hessabi M, Chen Z, Bressler J, et al. Seafood consumption and blood mercury concentrations in Jamaican children with and without autism spectrum disorders. Neurotox Res. 2013;23(1): 22-38. 
37. Blaurock-Busch E, Amin OR, Rabah T. Heavy metals and trace elements in hair and urine of a sample of Arab children with autistic spectrum disorder. Maedica (Buchar). 2011;6(4): 247-257.

38. Cobigo V, Murphy MS, Bielska IA, Ouellette-Kuntz H. Applying Hill's Criteria to the study of autism spectrum disorders and exposure to mercury. J Dev Disabil. 2012;18(1):20-33.

39. Ng DK, Chan $\mathrm{CH}$, Soo MT, Lee RS. Low-level chronic mercury exposure in children and adolescents: metaanalysis. Pediatr Int. 2007;49(1):80-87.

40. Agency for Toxic Substances and Disease Registry (US). Toxicological profile for mercury [Internet]. Atlanta (GA): Agency for Toxic Substances and Disease Registry; 1999 [cited 2014 March 1]. Available from: http://www.atsdr.cdc.gov/toxprofiles /tp46.pdf

41. Pichichero ME, Cernichiari E, Lopreiato J, Treanor J. Mercury concentrations and metabolism in infants receiving vaccines containing thiomersal: a descriptive study. Lancet. 2002;360(9347):1737-1741.

42. Chang S, Crothers C, Lai S, Lamm S. Pediatric neurobehavioral diseases in Nevada counties with respect to perchlorate in drinking water: an ecological inquiry. Birth Defects Res A Clin Mol Teratol. 2003;67(10):886-892.

43. St-Hilaire S, Ezike VO, Stryhn H, Thomas MA. An ecological study on childhood autism. Int J Health Geogr. 2012;11:44.

44. Becerra TA, Wilhelm M, Olsen J, Cockburn M, Ritz B. Ambient air pollution and autism in Los Angeles County, California. Environ Health Perspect. 2013;121(3):380-386.

45. Kalkbrenner AE, Daniels JL, Chen JC, Poole C, Emch M, Morrissey J. Perinatal exposure to hazardous air pollutants and autism spectrum disorders at age 8. Epidemiology. 2010;21(5):631-641.

46. Volk HE, Hertz-Picciotto I, Delwiche L, Lurmann F, McConnell R. Residential proximity to freeways and autism in the CHARGE study. Environ Health Perspect. 2011;119(6):873-877.
47. Volk HE, Lurmann F, Penfold B, Hertz-Picciotto I, McConnell R. Traffic-related air pollution, particulate matter, and autism. JAMA Psychiatry. 2013;70(1):71-77.

48. Windham GC, Zhang L, Gunier R, Croen LA, Grether JK. Autism spectrum disorders in relation to distribution of hazardous air pollutants in the San Francisco Bay area. Environ Health Perspect. 2006;114(9):1438-1444.

49. Castro-Giner F, Künzli N, Jacquemin B, Forsberg B, de Cid R, Sunyer J, et al. Traffic-related air pollution, oxidative stress genes, and asthma (ECHRS). Environ Health Perspect. 2009;117(12): 1919-1924.

50. Künzli N, Jerrett M, Garcia-Esteban $\mathrm{R}$, et al. Ambient air pollution and the progression of atherosclerosis in adults. PLoS One. 2010;5(2):e9096. doi: 10.1371/journal.pone.0009096.

51. Block ML, Calderón-Garcidueñas L. Air pollution: mechanisms of neuroinflammation and CNS disease. Trends Neurosci. 2009;32(9):506-516.

52. Wakefield AJ, Murch SH, Anthony A, et al. Ileal-lymphoid-nodular hyperplasia, non-specific colitis, and pervasive developmental disorder in children. Lancet. 1998;351(9103): 637-641.

53. Smeeth L, Cook C, Fombonne E, et al. MMR vaccination and pervasive developmental disorders: a casecontrol study. Lancet. 2004;364(9438): 963-969.

54. DeStefano F, Bhasin TK, Thompson WW, Yeargin-Allsopp M, Boyle C. Age at first measles-mumps-rubella vaccination in children with autism and school-matched control subjects: a population-based study in metropolitan Atlanta. Pediatrics. 2004;113(2): 259-266.

55. Mrozek-Budzyn D, Kieltyka A, Majewska R. Lack of association between measles-mumps-rubella vaccination and autism in children: a case-control study. Pediatr Infect Dis J. 2010;29(5):397-400.

56. Takahashi H, Suzumura S, Shirakizawa F, et al. An epidemiological study on Japanese autism concerning routine childhood immunization history. Jpn J Infect Dis. 2003;56(3):114-117.
57. Uno Y, Uchiyama $\mathrm{T}$, Kurosawa $\mathrm{M}$, Aleksic B, Ozaki N. The combined measles, mumps, and rubella vaccines and the total number of vaccines are not associated with development of autism spectrum disorder: the first case-control study in Asia. Vaccine. 2012;30(28): 4292-4298.

58. Hornig M, Briese T, Buie T, et al. Lack of association between measles virus vaccine and autism with enteropathy: a case-control study. PLoS One. 2008; 3(9):e3140.

59. Uchiyama $T$, Kurosawa M, Inaba Y. MMR-vaccine and regression in autism spectrum disorders: negative results presented from Japan. J Autism Dev Disord. 2007;37(2):210-217.

60. Baird G, Pickles A, Simonoff E, et al. Measles vaccination and antibody response in autism spectrum disorders. Arch Dis Child. 2008;93(10): 832-837.

61. Chen W, Landau S, Sham P, Fombonne E. No evidence for links between autism, MMR and measles virus. Psychol Med. 2004;34(3):543-553.

62. Honda H, Shimizu Y, Rutter M. No effect of MMR withdrawal on the incidence of autism: a total population study. J Child Psychol Psychiatry. 2005;46(6):572-579.

63. Shamberger RJ. Autism rates associated with nutrition and the WIC program. J Am Coll Nutr. 2011;30(5): 348-353.

64. Demicheli V, Jefferson T, Rivetti A, Price D. Vaccines for measles, mumps and rubella in children. Cochrane Database Syst Rev. 2005;(4)(4): CD004407.

65. Wilson K, Mills E, Ross C, McGowan J, Jadad A. Association of autistic spectrum disorder and the measles, mumps, and rubella vaccine: a systematic review of current epidemiological evidence. Arch Pediatr Adolesc Med. 2003;157(7):628-634

66. Geier DA, Geier MR. A comparative evaluation of the effects of MMR immunization and mercury doses from thimerosal-containing childhood vaccines on the population prevalence of autism. Med Sci Monit. 2004;10(3):PI33-PI39. 
67. Singh VK, Jensen RL. Elevated levels of measles antibodies in children with autism. Pediatr Neurol. 2003; 28(4):292-294.

68. Andrews N, Miller E, Grant A, Stowe J, Osborne V, Taylor B. Thimerosal exposure in infants and developmental disorders: a retrospective cohort study in the United Kingdom does not support a causal association. Pediatrics. 2004;114(3):584-591.

69. Price CS, Thompson WW, Goodson $B$, et al. Prenatal and infant exposure to thimerosal from vaccines and immunoglobulins and risk of autism. Pediatrics. 2010;126(4):656-664.

70. Hviid A, Stellfeld M, Wohlfahrt J, Melbye M. Association between thimerosal-containing vaccine and autism. JAMA. 2003;290(13):1763-1766.

71. Verstraeten T, Davis RL, DeStefano F, et al. Safety of thimerosal-containing vaccines: a two-phased study of computerized health maintenance organization databases. Pediatrics. 2003; 112(5):1039-1048.

72. Madsen KM, Lauritsen MB, Pedersen $\mathrm{CB}$, et al. Thimerosal and the occurrence of autism: negative ecological evidence from Danish population-based data. Pediatrics. 2003; 112(3 Pt 1):604-606.

73. Schechter R, Grether JK. Continuing increases in autism reported to California's developmental services system: mercury in retrograde. Arch Gen Psychiatry. 2008;65(1):19-24.

74. Stehr-Green P, Tull P, Stellfeld M, Mortenson PB, Simpson D. Autism and thimerosal-containing vaccines: lack of consistent evidence for an association. Am J Prev Med. 2003; 25(2):101-106.

75. Geier DA, Geier MR. A two-phased population epidemiological study of the safety of thimerosal-containing vaccines: a follow-up analysis. Med Sci Monit. 2005;11(4):CR160-170.

76. Geier MR, Geier DA. Neurodevelopmental disorders after thimerosalcontaining vaccines: a brief communication. Exp Biol Med (Maywood). 2003;228(6):660-664.
77. Young HA, Geier DA, Geier MR. Thimerosal exposure in infants and neurodevelopmental disorders: an assessment of computerized medical records in the Vaccine Safety Datalink. J Neurol Sci. 2008;271(1-2): 110-118.

78. Doja A, Roberts W. Immunizations and autism: a review of the literature. Can J Neurol Sci. 2006;33(4):341-346.

79. Singh VK, Hanson J. Assessment of metallothionein and antibodies to metallothionein in normal and autistic children having exposure to vaccine-derived thimerosal. Pediatr Allergy Immunol. 2006;17(4):291-296.

80. Singh VK, Rivas WH. Detection of antinuclear and antilaminin antibodies in autistic children who received thimerosal-containing vaccines. J Biomed Sci. 2004;11(5):607-610.

81. Miles JH, Takahashi TN. Lack of association between $\mathrm{Rh}$ status, $\mathrm{Rh}$ immune globulin in pregnancy and autism. Am J Med Genet A. 2007; 143A(13):1397-1407.

82. Croen LA, Matevia M, Yoshida CK, Grether JK. Maternal Rh D status, anti-D immune globulin exposure during pregnancy, and risk of autism spectrum disorders. Am J Obstet Gynecol. 2008;199(3):234.e1-e6.

83. Geier DA, Geier MR. A prospective study of thimerosal-containing Rho(D)immune globulin administration as a risk factor for autistic disorders. J Matern Fetal Neonatal Med. 2007; 20(5):385-390.

84. Geier DA, Mumper E, Gladfelter B, Coleman L, Geier MR. Neurodevelopmental disorders, maternal Rh-negativity, and Rho(D) immune globulins: a multi-center assessment. Neuro Endocrinol Lett. 2008;29(2): 272-280.

85. Fallon J. Could one of the most widely prescribed antibiotics amoxicillin/clavulanate "augmentin" be a risk factor for autism? Med Hypotheses. 2005;64(2):312-315.

86. Good P. Did acetaminophen provoke the autism epidemic? Altern Med Rev. 2009;14(4):364-372.
87. Harrington RA, Lee LC, Crum RM, Zimmerman AW, Hertz-Picciotto I. Serotonin hypothesis of autism: implications for selective serotonin reuptake inhibitor use during pregnancy. Autism Res. 2013;6(3):149-168.

88. Gur TL, Kim DR, Epperson CN. Central nervous system effects of prenatal selective serotonin reuptake inhibitors: sensing the signal through the noise. Psychopharmacology (Berl). 2013;227(4):567-582.

89. Croen LA, Grether JK, Yoshida CK, Odouli R, Hendrick V. Antidepressant use during pregnancy and childhood autism spectrum disorders. Arch Gen Psychiatry. 2011;68(11):1104-1112.

90. Rai D, Lee BK, Dalman C, Golding J, Lewis GH, Magnusson C. Parental depression, maternal antidepressant use during pregnancy, and risk of autism spectrum disorders: population based case-control study. BMJ. 2013;346:f2059.

91. Duncan S. Teratogenesis of sodium valproate. Curr Opin Neurol. 2007;20(2): 175-180.

92. Dufour-Rainfray D, Vourc'h P, Tourlet S, Guilloteau D, Chalon S, Andres CR. Fetal exposure to teratogens: evidence of genes involved in autism. Neurosci Biobehav Rev. 2011;35(5): 1254-1265.

93. Roullet FI, Lai JK, Foster JA. In utero exposure to valproic acid and autism-a current review of clinical and animal studies. Neurotoxicol Teratol. 2013;36: 47-56.

94. Christensen J, Grønborg TK, Sørensen MJ, et al. Prenatal valproate exposure and risk of autism spectrum disorders and childhood autism. JAMA. 2013; 309(16):1696-1703.

95. Adams JB, Romdalvik J, Ramanujam VM, Legator MS. Mercury, lead, and zinc in baby teeth of children with autism versus controls. J Toxicol Environ Health A. 2007;70(12): 1046-1051.

96. Atladóttir HÓ, Henriksen TB, Schendel DE, Parner ET. Autism after infection, febrile episodes, and antibiotic use during pregnancy: an exploratory study. Pediatrics. 2012; 130(6):e1447-e1454. 
97. Bauer AZ, Kriebel D. Prenatal and perinatal analgesic exposure and autism: an ecological link. Environ Health. 2013;12:41.

98. Schultz ST, Klonoff-Cohen HS, Wingard DL, Akshoomoff NA, Macera CA, Ji M. Acetaminophen (paracetamol) use, measles-mumpsrubella vaccination, and autistic disorder: the results of a parent survey. Autism. 2008;12(3):293-307.

99. Schultz ST. Can autism be triggered by acetaminophen activation of the endocannabinoid system? Acta Neurobiol Exp (Wars). 2010;70(2): 227-231.

100. Gardener H, Spiegelman D, Buka SL. Prenatal risk factors for autism: comprehensive meta-analysis. $\mathrm{Br} \mathrm{J}$ Psychiatry. 2009;195(1):7-14.

101. Bilder D, Pinborough-Zimmerman J, Miller J, McMahon W. Prenatal, perinatal, and neonatal factors associated with autism spectrum disorders. Pediatrics. 2009;123(5):1293-1300.

102. Burstyn I, Sithole F, Zwaigenbaum L. Autism spectrum disorders, maternal characteristics and obstetric complications among singletons born in Alberta, Canada. Chronic Dis Can. 2010;30(4):125-134.

103. Mann JR, McDermott S, Bao H, Hardin J, Gregg A. Pre-eclampsia, birth weight, and autism spectrum disorders. J Autism Dev Disord. 2010; 40(5):548-554.

104. Haglund NG, Källén KB. Risk factors for autism and Asperger syndrome. Perinatal factors and migration. Autism. 2011;15(2):163-183.

105. Lee BK, Gardner RM, Dal H, et al. Brief report: maternal smoking during pregnancy and autism spectrum disorders. J Autism Dev Disord. 2012; 42(9):2000-2005.

106. Visser JC, Rommelse N, Vink L, et al. Narrowly versus broadly defined autism spectrum disorders: differences in pre- and perinatal risk factors. J Autism Dev Disord. 2013;43(7): 1505-1516.

107. Tran PL, Lehti V, Lampi KM, Helenius $H$, Suominen A, Gissler $M$, et al. Smoking during pregnancy and risk of autism spectrum disorder in a Finnish national birth cohort. Paediatr Perinat Epidemiol. 2013;27(3):266-274.
108. Kalkbrenner AE, Braun JM, Durkin MS, et al. Maternal smoking during pregnancy and the prevalence of autism spectrum disorders, using data from the Autism and Developmental Disabilities Monitoring Network. Environ Health Perspect. 2012;120(7): 1042-1048.

109. Zhang X, Lv CC, Tian J, Miao RJ, Xi W, Hertz-Picciotto I, et al. Prenatal and perinatal risk factors for autism in China. J Autism Dev Disord. 2010; 40(11):1311-1321.

110. Eliasen M, Tolstrup JS, Nybo Andersen AM, Grønbaek M, Olsen J, StrandbergLarsen K. Prenatal alcohol exposure and autistic spectrum disorders-a population-based prospective study of 80,552 children and their mothers. Int J Epidemiol. 2010;39(4):1074-1081.

111. Mukherjee R, Layton M, Yacoub E, Turk J. Autism and autistic traits in people exposed to heavy prenatal alcohol: data from a clinical series of 21 individuals and nested case control study. Adv Ment Health Intellect Disabil. 2011;5(1):42-49.

112. Kolevzon A, Gross R, Reichenberg A. Prenatal and perinatal risk factors for autism: a review and integration of findings. Arch Pediatr Adolesc Med. 2007;161(4):326-333.

113. Hultman CM, Sandin S, Levine SZ, Lichtenstein P, Reichenberg A. Advancing paternal age and risk of autism: new evidence from a population-based study and a meta-analysis of epidemiological studies. Mol Psychiatry. 2011;16(12):1203-1212.

114. Sandin S, Hultman CM, Kolevzon A, Gross R, MacCabe JH, Reichenberg A. Advancing maternal age is associated with increasing risk for autism: a review and meta-analysis. J Am Acad Child Adolesc Psychiatry. 2012;51(5): 477-486.e1.

115. Frans EM, Sandin S, Reichenberg A, et al. Autism risk across generations: a population-based study of advancing grandpaternal and paternal age. JAMA Psychiatry. 2013;70(5):516-521.

116. van Balkom ID, Bresnahan M, Vuijk PJ, Hubert J, Susser E, Hoek HW. Paternal age and risk of autism in an ethnically diverse, non-industrialized setting: Aruba. PLoS One. 2012;7(9): e45090.
117. Parner ET, Baron-Cohen S, Lauritsen $\mathrm{MB}$, et al. Parental age and autism spectrum disorders. Ann Epidemiol. 2012;22(3):143-150.

118. Rahbar MH, Samms-Vaughan $M$, Loveland KA, et al. Maternal and paternal age are jointly associated with childhood autism in Jamaica. J Autism Dev Disord. 2012;42(9): 1928-1938.

119. Pinborough-Zimmerman J, Bilder D, Bakian A, et al. Sociodemographic risk factors associated with autism spectrum disorders and intellectual disability. Autism Res. 2011;4(6): 438-448.

120. Kong A, Frigge ML, Masson G, et al. Rate of de novo mutations and the importance of father's age to disease risk. Nature. 2012;488(7412):471-475.

121. Buizer-Voskamp JE, Blauw HM, Boks MP, van Eijk KR, Veldink JH, Hennekam EA, et al. Increased paternal age and the influence on burden of genomic copy number variation in the general population. Hum Genet. 2013;132(4):443-450.

122. Puleo CM, Reichenberg A, Smith CJ, Kryzak LA, Silverman JM. Do autism-related personality traits explain higher paternal age in autism? Mol Psychiatry. 2008;13(3):243-244.

123. Tsuchiya KJ, Matsumoto K, Miyachi $\mathrm{T}$, et al. Paternal age at birth and high-functioning autistic-spectrum disorder in offspring. Br J Psychiatry. 2008;193(4):316-321.

124. Lyall K, Pauls DL, Spiegelman D, Ascherio A, Santangelo SL. Pregnancy complications and obstetric suboptimality in association with autism spectrum disorders in children of the Nurses' Health Study II. Autism Res. 2012;5(1):21-30.

125. AL-Jammas IK, AL-Dobooni RMY. Prenatal and perinatal risk factors in autistic disorders. Arab J Psychiatr. 2012;23(2):108-114.

126. Durkin MS, Maenner MJ, Newschaffer $\mathrm{CJ}$, et al. Advanced parental age and the risk of autism spectrum disorder. Am J Epidemiol. 2008;168(11): 1268-1276. 
127. Croen LA, Najjar DV, Fireman B, Grether JK. Maternal and paternal age and risk of autism spectrum disorders. Arch Pediatr Adolesc Med. 2007;161(4):334-340.

128. Grether JK, Anderson MC, Croen LA, Smith D, Windham GC. Risk of autism and increasing maternal and paternal age in a large North American population. Am J Epidemiol. 2009;170(9):1118-1126.

129. King MD, Fountain C, Dakhlallah D, Bearman PS. Estimated autism risk and older reproductive age. Am J Public Health. 2009;99(9):1673-1679.

130. Shelton JF, Tancredi DJ, HertzPicciotto I. Independent and dependent contributions of advanced maternal and paternal ages to autism risk. Autism Res. 2010;3(1):30-39.

131. Hvidtjørn D, Grove J, Schendel D, et al. Risk of autism spectrum disorders in children born after assisted conception: a population-based follow-up study. J Epidemiol Community Health. 2011;65(6):497-502.

132. Hvidtjørn D, Schieve L, Schendel D, Jacobsson B, Sværke C, Thorsen P. Cerebral palsy, autism spectrum disorders, and developmental delay in children born after assisted conception: a systematic review and meta-analysis. Arch Pediatr Adolesc Med. 2009;163(1):72-83.

133. Zachor DA, Ben Itzchak E. Assisted reproductive technology and risk for autism spectrum disorder. Res Dev Disabil. 2011;32(6):2950-2956.

134. Shimada T, Kitamoto A, Todokoro A, et al. Parental age and assisted reproductive technology in autism spectrum disorders, attention deficit hyperactivity disorder, and Tourette syndrome in a Japanese population. Res Autism Spectr Disord. 2012;6(1): 500-507.

135. Sandin S, Nygren KG, Iliadou A, Hultman CM, Reichenberg A. Autism and mental retardation among offspring born after in vitro fertilization. JAMA. 2013;310(1):75-84.

136. Lyall K, Pauls DL, Spiegelman D, Santangelo SL, Ascherio A. Fertility therapies, infertility and autism spectrum disorders in the Nurses' Health Study II. Paediatr Perinat Epidemiol. 2012;26(4):361-372.
137. Grether JK, Qian Y, Croughan MS, et al. Is infertility associated with childhood autism? J Autism Dev Disord. 2013;43(3):663-672.

138. Lehti V, Brown AS, Gissler M, Rihko M, Suominen A, Sourander A. Autism spectrum disorders in IVF children: a national case-control study in Finland. Hum Reprod. 2013;28(3):812-818.

139. Krakowiak P, Walker CK, Bremer AA, et al. Maternal metabolic conditions and risk for autism and other neurodevelopmental disorders. Pediatrics. 2012;129(5):e1121-e1128.

140. Schrieken M, Visser J, Oosterling I, et al. Head circumference and height abnormalities in autism revisited: the role of pre- and perinatal risk factors. Eur Child Adolesc Psychiatry. 2013; 22(1):35-43

141. Dodds L, Fell DB, Shea S, Armson BA, Allen AC, Bryson S. The role of prenatal, obstetric and neonatal factors in the development of autism. J Autism Dev Disord. 2011;41(7):891-902.

142. Lyall K, Pauls DL, Santangelo SL, Spiegelman D, Ascherio A. Maternal early life factors associated with hormone levels and the risk of having a child with an autism spectrum disorder in the Nurses' Health Study II. J Autism Dev Disord. 2011;41(5):618-627.

143. Stein D, Weizman A, Ring A, Barak Y. Obstetric complications in individuals diagnosed with autism and in healthy controls. Compr Psychiatry. 2006;47(1): 69-75.

144. Buchmayer S, Johansson S, Johansson A, Hultman CM, Sparen P, Cnattingius S. Can association between preterm birth and autism be explained by maternal or neonatal morbidity? Pediatrics. 2009;124(5):e817-e825.

145. Nath S, Roy R, Mukherjee S. Perinatal complications associated with autisma case control study in a neurodevelopment and early intervention clinic. J Indian Med Assoc. 2012; 110(8):526-529.

146. Hönekopp J. Digit ratio 2D:4D in relation to autism spectrum disorders, empathizing, and systemizing: a quantitative review. Autism Res. 2012;5(4): 221-230.
147. de Bruin EI, Verheij F, Wiegman T, Ferdinand RF. Differences in finger length ratio between males with autism, pervasive developmental disorder-not otherwise specified, ADHD, and anxiety disorders. Dev Med Child Neurol. 2006;48(12): 962-965

148. Whitehouse AJ, Mattes E, Maybery MT, Dissanayake C, Sawyer M, Jones RM, et al. Perinatal testosterone exposure and autistic-like traits in the general population: a longitudinal pregnancy-cohort study. J Neurodev Disord. 2012;4(1):25.

149. de Cock M, Maas YG, van de Bor M. Does perinatal exposure to endocrine disruptors induce autism spectrum and attention deficit hyperactivity disorders? Review. Acta Paediatr. 2012; $101(8): 811-818$.

150. Kellman R. The thyroid-autism connection. Exceptional Parent. 2010; 40(4):16.

151. Román GC. Autism: transient in utero hypothyroxinemia related to maternal flavonoid ingestion during pregnancy and to other environmental antithyroid agents. J Neurol Sci. 2007; 262(1-2):15-26.

152. Soldin OP, Lai S, Lamm SH, Mosee S. Lack of a relation between human neonatal thyroxine and pediatric neurobehavioral disorders. Thyroid. 2003; 13(2):193-198.

153. Hoshiko S, Grether JK, Windham GC, Smith D, Fessel K. Are thyroid hormone concentrations at birth associated with subsequent autism diagnosis? Autism Res. 2011;4(6): 456-463

154. Korzeniewski SJ, Pinto-Martin JA, Whitaker $\mathrm{AH}$, et al. Association between transient hypothyroxinaemia of prematurity and adult autism spectrum disorder in a low-birthweight cohort: an exploratory study. Paediatr Perinat Epidemiol. 2013;27(2):182-187.

155. Wallace AE, Anderson GM, Dubrow R. Obstetric and parental psychiatric variables as potential predictors of autism severity. J Autism Dev Disord. 2008;38(8):1542-1554. 
156. Langridge AT, Glasson EJ, Nassar N, et al. Maternal conditions and perinatal characteristics associated with autism spectrum disorder and intellectual disability. PLoS One. 2013;8(1): e50963.

157. Gardener H, Spiegelman D, Buka SL. Perinatal and neonatal risk factors for autism: a comprehensive metaanalysis. Pediatrics. 2011;128(2): 344-355.

158. Losh M, Esserman D, Anckarsäter H, Sullivan PF, Lichtenstein P. Lower birth weight indicates higher risk of autistic traits in discordant twin pairs. Psychol Med. 2012;42(5):1091-1102.

159. Lampi KM, Lehtonen L, Tran PL, et al. Risk of autism spectrum disorders in low birth weight and small for gestational age infants. J Pediatr. 2012; 161(5):830-836.

160. Ben Itzchak E, Lahat E, Zachor DA. Advanced parental ages and low birth weight in autism spectrum disordersrates and effect on functioning. Res Dev Disabil. 2011;32(5):1776-1781.

161. Leavey A, Zwaigenbaum L, Heavner K, Burstyn I. Gestational age at birth and risk of autism spectrum disorders in Alberta, Canada. J Pediatr. 2013; 162(2):361-368.

162. Treyvaud K, Ure A, Doyle LW, et al. Psychiatric outcomes at age seven for very preterm children: rates and predictors. J Child Psychol Psychiatry. 2013;54(7):772-779.

163. Movsas TZ, Paneth N. The effect of gestational age on symptom severity in children with autism spectrum disorder. J Autism Dev Disord. 2012; 42(11):2431-2439.

164. Moore GS, Kneitel AW, Walker CK, Gilbert WM, Xing G. Autism risk in small- and large-for-gestational-age infants. Am J Obstet Gynecol. 2012; 206(4):314.e1-e9.

165. Abel KM, Dalman C, Svensson AC, et al. Deviance in fetal growth and risk of autism spectrum disorder. Am J Psychiatry. 2013;170(4):391-398.

166. Brimacombe M, Ming X, Lamendola M. Prenatal and birth complications in autism. Matern Child Health J. 2007;11(1):73-79.
167. Tudor ME, DeVincent CJ, Gadow KD. Prenatal pregnancy complications and psychiatric symptoms: Children with ASD versus clinic controls. Res Autism Spectr Disord. 2012;6(4): 1401-1405.

168. Glasson EJ, Bower C, Petterson B, de Klerk N, Chaney G, Hallmayer JF. Perinatal factors and the development of autism: a population study. Arch Gen Psychiatry. 2004;61(6):618-627.

169. Gillberg C, Cederlund M. Asperger syndrome: familial and pre- and perinatal factors. J Autism Dev Disord. 2005;35(2):159-166.

170. Burstyn I, Wang X, Yasui Y, Sithole F, Zwaigenbaum L. Autism spectrum disorders and fetal hypoxia in a population-based cohort: accounting for missing exposures via EstimationMaximization algorithm. BMC Med Res Methodol. 2011;11:2.

171. Schmidt K, Zimmerman A, Bauman $\mathrm{M}$, et al. Brief report: Asperger's syndrome and sibling birth order. J Autism Dev Disord. 2013;43(4):973-977.

172. Leonard H, Glasson E, Nassar N, et al. Autism and intellectual disability are differentially related to sociodemographic background at birth PLoS One. 2011;6(3):e17875.

173. Reichenberg A, Smith C, Schmeidler J, Silverman JM. Birth order effects on autism symptom domains. Psychiatry Res. 2007;150(2):199-204.

174. Martin LA, Horriat NL. The effects of birth order and birth interval on the phenotypic expression of autism spectrum disorder. PLoS One. 2012; 7(11):e51049.

175. Cheslack-Postava K, Liu K, Bearman PS. Closely spaced pregnancies are associated with increased odds of autism in California sibling births. Pediatrics. 2011;127(2):246-253.

176. Williams K, Helmer M, Duncan GW, Peat JK, Mellis CM. Perinatal and maternal risk factors for autism spectrum disorders in New South Wales, Australia. Child Care Health Dev. 2008;34(2):249-256.
177. Van Naarden Braun K, Schieve L, Daniels J, et al. Relationships between multiple births and autism spectrum disorders, cerebral palsy, and intellectual disabilities: Autism and Developmental Disabilities Monitoring (ADDM) Network-2002 surveillance year. Autism Res. 2008;1(5):266-274.

178. Zerbo O, Iosif AM, Delwiche L, Walker C, Hertz-Picciotto I. Month of conception and risk of autism. Epidemiology. 2011;22(4):469-475.

179. Hebert KJ, Miller LL, Joinson CJ. Association of autistic spectrum disorder with season of birth and conception in a UK cohort. Autism Res. 2010;3(4):185-190.

180. Lee LC, Newschaffer CJ, Lessler JT, Lee BK, Shah R, Zimmerman AW. Variation in season of birth in singleton and multiple births concordant for autism spectrum disorders. Paediatr Perinat Epidemiol. 2008;22(2): 172-179.

181. Mazumdar S, Liu KY, Susser E, Bearman P. The disappearing seasonality of autism conceptions in California. PLoS One. 2012;7(7):e41265.

182. Cohly HH, Panja A. Immunological findings in autism. Int Rev Neurobiol. 2005;71:317-341

183. Grether JK, Croen LA, Anderson MC, Nelson KB, Yolken RH. Neonatally measured immunoglobulins and risk of autism. Autism Res. 2010;3(6): 323-332.

184. Croen LA, Braunschweig D, Haapanen $\mathrm{L}$, et al. Maternal mid-pregnancy autoantibodies to fetal brain protein: the early markers for autism study. Biol Psychiatry. 2008;64(7):583-588.

185. Braunschweig D, Ashwood P, Krakowiak P, et al. Autism: maternally derived antibodies specific for fetal brain proteins. Neurotoxicology. 2008;29(2):226-231.

186. Braunschweig D, Krakowiak P, Duncanson P, et al. Autism-specific maternal autoantibodies recognize critical proteins in developing brain. Transl Psychiatry. 2013;3:e277.

187. Ramaekers VT, Blau N, Sequeira JM, Nassogne MC, Quadros EV. Folate receptor autoimmunity and cerebral folate deficiency in low-functioning autism with neurological deficits. Neuropediatrics. 2007;38(6):276-281. 
188. Rothenberg SP, da Costa MP, Sequeira $\mathrm{JM}$, et al. Autoantibodies against folate receptors in women with a pregnancy complicated by a neuraltube defect. N Engl J Med. 2004; 350(2):134-142.

189. Ramaekers VT, Quadros EV, Sequeira JM. Role of folate receptor autoantibodies in infantile autism. Mol Psychiatry. 2013;18(3):270-271.

190. Atladóttir HO, Pedersen MG, Thorsen $P$, et al. Association of family history of autoimmune diseases and autism spectrum disorders. Pediatrics. 2009; 124(2):687-694.

191. Molloy CA, Morrow AL, MeinzenDerr $\mathrm{J}$, et al. Familial autoimmune thyroid disease as a risk factor for regression in children with autism spectrum disorder: a CPEA Study. J Autism Dev Disord. 2006;36(3):317-324.

192. Croen LA, Grether JK, Yoshida CK, Odouli R, Van de Water J. Maternal autoimmune diseases, asthma and allergies, and childhood autism spectrum disorders: a case-control study. Arch Pediatr Adolesc Med. 2005; 159(2):151-157.

193. Margutti P, Delunardo F, Ortona E. Autoantibodies associated with psychiatric disorders. Curr Neurovasc Res. 2006;3(2):149-157.

194. Vincent A, Dalton P, Clover L, Palace J, Lang B. Antibodies to neuronal targets in neurological and psychiatric diseases. Ann N Y Acad Sci. 2003; 992:48-55.

195. Fox E, Amaral D, Van de Water J. Maternal and fetal antibrain antibodies in development and disease. Dev Neurobiol. 2012;72(10):1327-1334.

196. Ashwood P, Van de Water J. Is autism an autoimmune disease? Autoimmun Rev. 2004;3(7-8):557-562.

197. Dietert RR, Dietert JM. Potential for early-life immune insult including developmental immunotoxicity in autism and autism spectrum disorders: focus on critical windows of immune vulnerability. J Toxicol Environ Health B Crit Rev. 2008;11(8):660-680.

198. Hagberg H, Gressens P, Mallard C. Inflammation during fetal and neonatal life: implications for neurologic and neuropsychiatric disease in children and adults. Ann Neurol. 2012;71(4): 444-457.
199. Blaylock RL, Strunecka A. Immuneglutamatergic dysfunction as a central mechanism of the autism spectrum disorders. Curr Med Chem. 2009; 16(2):157-170.

200. Blaylock RL. A possible central mechanism in autism spectrum disorders, part 3: the role of excitotoxin food additives and the synergistic effects of other environmental toxins. Altern Ther Health Med. 2009;15(2): 56-60.

201. Abdallah MW, Larsen N, Grove J, Nørgaard-Pedersen B, Thorsen P, Mortensen EL, et al. Amniotic fluid chemokines and autism spectrum disorders: an exploratory study utilizing a Danish Historic Birth Cohort. Brain Behav Immun. 2012;26(1): 170-176.

202. Chez MG, Dowling T, Patel PB, Khanna P, Kominsky M. Elevation of tumor necrosis factor-alpha in cerebrospinal fluid of autistic children. Pediatr Neurol. 2007;36(6):361-365.

203. Ashwood P, Krakowiak P, HertzPicciotto I, Hansen R, Pessah IN, Van de Water J. Altered T cell responses in children with autism. Brain Behav Immun. 2011;25(5):840-849.

204. Abdallah MW, Larsen N, Mortensen EL, et al. Neonatal levels of cytokines and risk of autism spectrum disorders: an exploratory register-based historic birth cohort study utilizing the Danish Newborn Screening Biobank. J Neuroimmunol. 2012; 252(1-2):75-82.

205. Abdallah MW, Larsen N, Grove J, et al. Neonatal chemokine levels and risk of autism spectrum disorders: findings from a Danish historic birth cohort follow-up study. Cytokine. 2013;61(2):370-376.

206. Brown AS. Epidemiologic studies of exposure to prenatal infection and risk of schizophrenia and autism. Dev Neurobiol. 2012;72(10):1272-1276.

207. Zerbo O, Iosif AM, Walker C, Ozonoff $S$, Hansen RL, Hertz-Picciotto I. Is maternal influenza or fever during pregnancy associated with autism or developmental delays? Results from the CHARGE (CHildhood Autism Risks from Genetics and Environment) study. J Autism Dev Disord. 2013; 43(1):25-33.
208. Maimburg RD, Vaeth M. Perinatal risk factors and infantile autism. Acta Psychiatr Scand. 2006;114(4):257-264.

209. Maimburg RD, Vaeth M, Schendel $\mathrm{DE}$, Bech BH, Olsen J, Thorsen P. Neonatal jaundice: a risk factor for infantile autism? Paediatr Perinat Epidemiol. 2008;22(6):562-568.

210. Maimburg RD, Bech BH, Væth M, Møller-Madsen B, Olsen J. Neonatal jaundice, autism, and other disorders of psychological development. Pediatrics. 2010;126(5):872-878.

211. Croen LA, Yoshida CK, Odouli R, Newman TB. Neonatal hyperbilirubinemia and risk of autism spectrum disorders. Pediatrics. 2005;115(2): e135-e138.

212. Zhang Y, Xu Q, Liu J, Li S, Xu X. Risk factors for autistic regression: results of an ambispective cohort study. J Child Neurol. 2012;27(8):975-981.

213. Saemundsen E, Ludvigsson P, Rafnsson V. Risk of autism spectrum disorders after infantile spasms: a population-based study nested in a cohort with seizures in the first year of life. Epilepsia. 2008;49(11): 1865-1870.

214. Numis AL, Major P, Montenegro MA, Muzykewicz DA, Pulsifer MB, Thiele EA. Identification of risk factors for autism spectrum disorders in tuberous sclerosis complex. Neurology. 2011;76(11):981-987.

215. Vergani L, Cristina L, Paola R, et al. Metals, metallothioneins and oxidative stress in blood of autistic children. Res Autism Spectr Disord. 2011; 5(1):286-293.

216. Obrenovich ME, Shamberger RJ, Lonsdale D. Altered heavy metals and transketolase found in autistic spectrum disorder. Biol Trace Elem Res. 2011;144(1-3):475-486.

217. El-Ansary A, Al-Daihan S, Al-Dbass A, Al-Ayadhi L. Measurement of selected ions related to oxidative stress and energy metabolism in Saudi autistic children. Clin Biochem. 2010;43(1-2):63-70.

218. Parellada M, Moreno C, Mac-Dowell $\mathrm{K}$, et al. Plasma antioxidant capacity is reduced in Asperger syndrome. $\mathrm{J}$ Psychiatr Res. 2012;46(3):394-401. 
219. Blaurock-Busch E, Amin OR, Dessoki $\mathrm{HH}$, Rabah T. Toxic metals and essential elements in hair and severity of symptoms among children with autism. Maedica (Buchar). 2012;7(1): 38-48.

220. Lakshmi Priya MD, Geetha A. Level of trace elements (copper, zinc, magnesium and selenium) and toxic elements (lead and mercury) in the hair and nail of children with autism. Biol Trace Elem Res. 2011;142(2): 148-158.

221. Yasuda H, Yoshida K, Yasuda Y, Tsutsui $\mathrm{T}$. Infantile zinc deficiency: association with autism spectrum disorders. Sci Rep. 2011;1:129.

222. Al-Farsi YM, Waly MI, Al-Sharbati MM, et al. Levels of heavy metals and essential minerals in hair samples of children with autism in Oman: a case-control study. Biol Trace Elem Res. 2013;151(2):181-186.

223. Al-Ayadhi LY. Heavy metals and trace elements in hair samples of autistic children in central Saudi Arabia. Neurosciences (Riyadh). 2005;10(3): 213-218.

224. Chen MH, Su TP, Chen YS, et al. Association between psychiatric disorders and iron deficiency anemia among children and adolescents: a nationwide population-based study. BMC Psychiatry. 2013;13:161.

225. De Palma G, Catalani S, Franco A, Brighenti M, Apostoli P. Lack of correlation between metallic elements analyzed in hair by ICP-MS and autism. J Autism Dev Disord. 2012; 42(3):342-353.

226. Wright B, Pearce H, Allgar V, et al. A comparison of urinary mercury between children with autism spectrum disorders and control children. PLoS One. 2012;7(2):e29547.

227. Meguid NA, Hashish AF, Anwar M, Sidhom G. Reduced serum levels of 25-hydroxy and 1,25-dihydroxy vitamin D in Egyptian children with autism. J Altern Complement Med. 2010;16(6):641-645.

228. Yorbik O, Kurt I, Hasimi A, Oztürk O. Chromium, cadmium, and lead levels in urine of children with autism and typically developing controls. Biol Trace Elem Res. 2010;135(1-3):10-15.
229. Abdullah MM, Ly AR, Goldberg WA, et al. Heavy metal in children's tooth enamel: related to autism and disruptive behaviors? J Autism Dev Disord. 2012;42(6):929-936.

230. Kočovská E, Fernell E, Billstedt E, Minnis H, Gillberg C. Vitamin D and autism: clinical review. Res Dev Disabil. 2012;33(5):1541-1550.

231. DeLuca GC, Kimball SM, Kolasinski J, Ramagopalan SV, Ebers GC. Review: the role of vitamin $\mathrm{D}$ in nervous system health and disease. Neuropathol Appl Neurobiol. 2013;39(5):458-484.

232. Grant WB, Soles CM. Epidemiologic evidence supporting the role of maternal vitamin $\mathrm{D}$ deficiency as a risk factor for the development of infantile autism. Dermatoendocrinol. 2009;1(4):223-228.

233. Dealberto MJ. Prevalence of autism according to maternal immigrant status and ethnic origin. Acta Psychiatr Scand. 2011;123(5):339-348.

234. Fernell E, Barnevik-Olsson M, Bågenholm G, Gillberg C, Gustafsson S, Sääf M. Serum levels of 25-hydroxyvitamin $\mathrm{D}$ in mothers of Swedish and of Somali origin who have children with and without autism. Acta Paediatr. 2010;99(5):743-747.

235. Whitehouse AJ, Holt BJ, Serralha M, Holt PG, Hart PH, Kusel MM. Maternal vitamin D levels and the autism phenotype among offspring. J Autism Dev Disord. 2013;43(7): 1495-1504.

236. Al-Farsi YM, Al-Sharbati MM, Waly MI, et al. Effect of suboptimal breastfeeding on occurrence of autism: a case-control study. Nutrition. 2012; 28(7-8):e27-e32.

237. Schultz ST, Klonoff-Cohen HS, Wingard DL, et al. Breastfeeding, infant formula supplementation, and autistic disorder: the results of a parent survey. Int Breastfeed J. 2006;1:16.

238. Surén $\mathrm{P}$, Roth $\mathrm{C}$, Bresnahan $\mathrm{M}$, et al. Association between maternal use of folic acid supplements and risk of autism spectrum disorders in children. JAMA. 2013;309(6):570-577.

239. Beard CM, Panser LA, Katusic SK. Is excess folic acid supplementation a risk factor for autism? Med Hypotheses. 2011;77(1):15-17.
240. Maenner MJ, Arneson CL, Durkin MS. Socioeconomic disparity in the prevalence of autism spectrum disorder in Wisconsin. WMJ. 2009;108(5): 253-255.

241. Thomas P, Zahorodny W, Peng B, et al. The association of autism diagnosis with socioeconomic status. Autism. 2012;16(2):201-213.

242. Bhasin TK, Schendel D. Sociodemographic risk factors for autism in a US metropolitan area. J Autism Dev Disord. 2007;37(4):667-677.

243. Emerson E. Deprivation, ethnicity and the prevalence of intellectual and developmental disabilities. J Epidemiol Community Health. 2012;66(3):218-224.

244. Rai D, Lewis G, Lundberg M, et al. Parental socioeconomic status and risk of offspring autism spectrum disorders in a Swedish populationbased study. J Am Acad Child Adolesc Psychiatry. 2012;51(5):467-476.e6.

245. Van Meter KC, Christiansen LE, Delwiche LD, Azari R, Carpenter TE, Hertz-Picciotto I. Geographic distribution of autism in California: a retrospective birth cohort analysis. Autism Res. 2010;3(1):19-29.

246. Mandell DS, Wiggins LD, Carpenter LA, et al. Racial/ethnic disparities in the identification of children with autism spectrum disorders. Am J Public Health. 2009;99(3):493-498.

247. Keen DV, Reid FD, Arnone D. Autism, ethnicity and maternal immigration. Br J Psychiatry. 2010;196(4):274-281.

248. Williams PG, Hersh JH, Allard AM, Sears LL. A controlled study of mercury levels in hair samples of children with autism as compared to their typically developing siblings. Res Autism Spectr Disord. 2008;2(1): 170-175.

249. Magnusson C, Rai D, Goodman A, et al. Migration and autism spectrum disorder: population-based study. Br J Psychiatry. 2012;201:109-115.

250. van der Ven E, Termorshuizen F, Laan W, Breetvelt EJ, van Os J, Selten JP. An incidence study of diagnosed autism-spectrum disorders among immigrants to the Netherlands. Acta Psychiatr Scand. 2013;128(1):54-60. 
251. Fountain C, Bearman P. Risk as social context: immigration policy and autism in California. Sociol Forum (Randolph N J). 2011;26(2):215-240.

252. Kinney DK, Munir KM, Crowley DJ, Miller AM. Prenatal stress and risk for autism. Neurosci Biobehav Rev. 2008;32(8):1519-1532.

253. O’Donnell K, O’Connor TG, Glover V. Prenatal stress and neurodevelopment of the child: focus on the HPA axis and role of the placenta. Dev Neurosci. 2009;31(4):285-292.

254. Roberts AL, Lyall K, Rich-Edwards JW, Ascherio A, Weisskopf MG. Association of maternal exposure to childhood abuse with elevated risk for autism in offspring. JAMA Psychiatry. 2013;70(5):508-515.

255. Rai D, Golding J, Magnusson C, Steer C, Lewis G, Dalman C. Prenatal and early life exposure to stressful life events and risk of autism spectrum disorders: population-based studies in Sweden and England. PLoS One. 2012;7(6):e38893.

256. Grether JK, Li SX, Yoshida CK, Croen LA. Antenatal ultrasound and risk of autism spectrum disorders. J Autism Dev Disord. 2010;40(2):238-245.

257. Lathe R. Microwave electromagnetic radiation and autism. E J Appl Psychol. 2009;5(1):11-30.

258. Stoch YK, Williams CJ, Granich J, et al. Are prenatal ultrasound scans associated with the autism phenotype? Follow-up of a randomised controlled trial. J Autism Dev Disord. 2012;42(12):2693-2701.

259. Golding J, Steer C, Pembrey $M$. Parental and grandparental ages in the autistic spectrum disorders: a birth cohort study. PLoS One. 2010; 5(4):e9939.

260. Majewska MD, Urbanowicz E, RokBujko P, Namyslowska I, Mierzejewski P. Age-dependent lower or higher levels of hair mercury in autistic children than in healthy controls. Acta Neurobiol Exp (Wars). 2010; 70(2):196-208.

261. Geier DA, Audhya T, Kern JK, Geier MR. Blood mercury levels in autism spectrum disorder: is there a threshold level? Acta Neurobiol Exp (Wars). 2010;70:177-186.
262. DeSoto MC, Hitlan RT. Blood levels of mercury are related to diagnosis of autism: a reanalysis of an important data set. J Child Neurol. 2007;22(11): 1308-1311.

263. Fido A, Al-Saad S. Toxic trace elements in the hair of children with autism. Autism. 2005;9(3):290-298.

264. Geier DA, Kern JK, King PG, Sykes LK, Geier MR. Hair toxic metal concentrations and autism spectrum disorder severity in young children. Int J Environ Res Public Health. 2012;9(12):4486-4497.

265. Williams PG, Hersh JH, Allard AM, Sears LL. A controlled study of mercury levels in hair samples of children with autism as compared to their typically developing siblings. Res Autism Spectr Disord. 2008;2(1): 170-175.

266. Albizzati A, Morè L, Di Candia D, Saccani M, Lenti C. Normal concentrations of heavy metals in autistic spectrum disorders. Minerva Pediatr. 2012;64(1):27-31.

267. Kern JK, Grannemann BD, Trivedi MH, Adams JB. Sulfhydryl-reactive metals in autism. J Toxicol Environ Health A. 2007;70(8):715-721.

268. El-Ansary AK, Bacha AB, Ayadhi LY. Relationship between chronic lead toxicity and plasma neurotransmitters in autistic patients from Saudi Arabia. Clin Biochem. 2011;44(13):1116-1120.

269. Health Canada. Report on human biomonitoring of environmental chemicals in Canada: results of the Canadian Health Measures Survey Cycle 1 (2007-2009) [Internet]. Ottawa $(\mathrm{ON})$ : Minister of Health (Canada); 2010 Aug [cited 2014 March 1]. Available from: http://www.hc-sc.gc.ca /ewh-semt/alt_formats/hecs-sesc /pdf/pubs/contaminants/chms -ecms/report-rapport-eng.pdf

270. Health Canada. Human health risk assessment of mercury in fish and health benefits of fish consumption [Internet]. Ottawa (ON): Minister of Health (Canada); 2007 March [cited 2014 March 1]. Available from: http:// publications.gc.ca/collections /collection_2007/hc-sc/H164-54 -2007E.pdf
271. Agency for Toxic Substances and Disease Registry (US). Toxicological profile for aluminum [Internet]. Atlanta (GA): Agency for Toxic Substances and Disease Registry; 2008 [cited 2014 March 1]. Available from: http://www.atsdr.cdc.gov /toxprofiles/tp22.pdf

272. Agency for Toxic Substances and Disease Registry (US). Toxicological profile for lead [Internet]. Atlanta (GA): Agency for Toxic Substances and Disease Registry; 2007 [cited 2014 March 1]. Available from: http://www.atsdr.cdc.gov/toxprofiles /tp13.pdf

273. Agency for Toxic Substances and Disease Registry (US). Toxicological profile for arsenic [Internet]. Atlanta (GA): Agency for Toxic Substances and Disease Registry; 2007 [cited 2014 March 1]. Available from: http://www.atsdr.cdc.gov/toxprofiles $/$ tp2.pdf 